\title{
Linking atmospheric synoptic transport, cloud phase, surface energy fluxes, and sea-ice growth: observations of midwinter SHEBA conditions
}

\author{
P. Ola G. Persson ${ }^{1,2}$ - Matthew D. Shupe ${ }^{1,2} \cdot$ Don Perovich ${ }^{3,4} \cdot$ Amy Solomon $^{1,2}$
}

Received: 31 December 2015 / Accepted: 2 October 2016 / Published online: 12 October 2016

(C) The Author(s) 2016. This article is published with open access at Springerlink.com

\begin{abstract}
Observations from the Surface Heat Budget of the Arctic Ocean (SHEBA) project are used to describe a sequence of events linking midwinter long-range advection of atmospheric heat and moisture into the Arctic Basin, formation of supercooled liquid water clouds, enhancement of net surface energy fluxes through increased downwelling longwave radiation, and reduction in near-surface conductive heat flux loss due to a warming of the surface, thereby leading to a reduction in sea-ice bottom growth. The analyses provide details of two events during Jan. 1-12, 1998, one entering the Arctic through Fram Strait and the other from northeast Siberia; winter statistics extend the results. Both deep, precipitating frontal clouds and post-frontal stratocumulus clouds impact the surface radiation and energy budget. Cloud liquid water, occurring preferentially in stratocumulus clouds extending into the base of the inversion, provides the strongest impact on surface radiation and hence modulates the surface forcing, as found previously. The observations suggest a minimum water vapor threshold, likely case dependent, for producing liquid water clouds. Through responses to the radiative forcing and surface warming, this cloud liquid water also
\end{abstract}

P. Ola G. Persson

ola.persson@colorado.edu

1 Cooperative Institute for Research in Environmental Sciences, University of Colorado, Campus Box 216, Boulder, CO 80309, USA

2 Earth System Research Laboratory, Physical Sciences Division, National Oceanographic and Atmospheric Administration, Boulder, CO 80305, USA

3 Cold Regions Research and Engineering Laboratory, Hanover, NH 03755, USA

4 Thayer School of Engineering, Dartmouth College, Hanover, NH 03755, USA modulates the turbulent and conductive heat fluxes, and produces a thermal wave penetrating into the sea ice. About $20-33 \%$ of the observed variations of bottom ice growth can be directly linked to variations in surface conductive heat flux, with retarded ice growth occurring several days after these moisture plumes reduce the surface conductive heat flux. This sequence of events modulate pack-ice wintertime environmental conditions and total ice growth, and has implications for the annual sea-ice evolution, especially for the current conditions of extensive thinner ice.

Keywords Atmospheric heat and moisture advection . Mixed-phase Arctic clouds · Radiative forcing · Arctic surface energy budget $\cdot$ Sea-ice growth

\section{Introduction}

The Arctic Ocean is a region approximately the size of the United States and whose climate is changing at a rate more rapidly than elsewhere on the globe. Some of the physical processes important for understanding the Arctic Ocean climate are unique to that region, and, because of logistical constraints due to the inhospitable environment, measurements of these processes are few. This often leads to poor representations of such processes in current models, including global and regional climate models, weather forecasting models and reanalyses.

Processes key for understanding the Arctic Ocean climate system include those affecting clouds, boundary-layer structure, surface energy fluxes, and sea-ice characteristics, such as ice concentration, thickness, and albedo. Interactions among clouds, the atmospheric boundary layer, and the sea-ice surface are complex, with processes in one component often dependent on processes in another. A full 
understanding of processes in one component is only possible with substantial understanding of those in others (e.g., Sterk et al. 2013). For instance, cloud macro- and microphysical properties are key modulators of downwelling radiative fluxes and these properties in turn are dependent on moisture availability, dynamical forcing, and cloud condensation and ice nuclei. The moisture, forcing, and aerosol environments of clouds are generally determined by some balance of large-scale synoptic/mesoscale processes, local surface characteristics, and boundary-layer stability and processes. In turn, the radiative forcing of the surface due to cloud characteristics impacts the boundary-layer stability and vertical movement of moisture and aerosols. Our ability to understand and quantitatively model these coupled processes and feedbacks is crucial both for the emerging need of short-term weather forecasting in the changing Arctic and for reliably representing these processes in regional and global climate models and their responses to changes in forcing.

Processes in the Arctic cloud-atmospheric boundary layer-surface system have historically been studied individually, but it is only recently that their close interaction has been recognized. Persson et al. (1999) showed that net longwave radiation over the wintertime Arctic sea ice has a bimodal distribution that was produced by the presence (or not) of liquid water in clouds, and that this bimodal cloud forcing produces large, sudden, surface temperature changes and bimodal responses in other surface energy budget terms. These cloud-surface interactions have since been discussed by others who have suggested that these two radiative peaks represent distinct "atmospheric states" (e.g., Shupe and Intrieri 2004; Stramler et al. 2011; Morrison et al. 2012; Engström et al. 2014). Pithan et al. (2014) also utilized these atmospheric states and associated cloudsurface process relationships from observations and model output to evaluate the physical processes and interactions in CMIP5 climate models. Only the few models capable of producing strongly supercooled liquid water in mixed phase clouds were able to produce both states, though even some of these had erroneous low-level stability because of improper responses in the turbulent heat fluxes.

Sterk et al. (2013) explored a wider range of process interactions over sea ice using unique process-relationship diagnostics of output from a simple model. Their analysis illustrated the strong and complex dependence among the atmospheric state, atmospheric radiative forcing, turbulent atmospheric heat flux, and conductive heat flux in the ice. While their study illustrates the complexity of the interactions, their results are dependent on their model physics. However, similar diagnostics can be done with observations, were they available, that would provide quantitative insights into real world interactions. These could be used to validate the models.
The physical processes important for atmospherecloud-surface interactions over sea ice are not only local processes but also include transport mechanisms for heat, moisture and aerosols, as illustrated by Persson (2012) and mentioned by Pithan et al. (2014). Recent studies using reanalysis data have shown the importance of transport "gateways" into the wintertime Arctic. Woods et al. (2013) found that the Fram Strait was a major gateway for winter moisture transport, though other gateways such as the Bering Strait near Alaska were also important. These moisture intrusions have been statistically shown to have an important impact on the Arctic surface energy budget, with a strong increase in downward longwave radiation being hypothesized as the primary forcing mechanism produced by the moisture intrusions (Doyle et al. 2011). Studies have shown the importance of northward penetration of moisture plumes, often called "atmospheric rivers", for mid-latitude precipitation events (e.g., Zhu and Newell 1998; Ralph et al. 2004; Neiman et al. 2008), for triggering spring or summer melt events over the Arctic sea ice (Persson 2012; Tjernström et al. 2015), and for triggering rare melt events on the Greenland ice cap (Neff et al. 2014).

Previous studies mentioned above focused on moisture transport and in some cases its impact on downwelling longwave radiation, and used observations, model output, and reanalysis data. An emphasis of the observational studies has been on spring or summer melt impacts of such plumes; winter studies over sea ice using primarily observational data have not been done. This study uses primarily observational data during Arctic midwinter to show the link between episodic penetration of atmospheric moisture plumes into the Arctic, cloud phase, and modulation of midwinter sea-ice growth. The analysis reveals the complex synoptic evolution, its impact on the clouds, and the clouds' impact on the surface processes. It is unique for its detailed illustration of interactions between the different processes and for providing new quantitative linkages between some of them. The linkage of atmospheric processes to heat conduction in sea ice and ice growth is unique. Since midwinter Arctic process studies over sea ice are particularly lacking, this study also fills a unique niche for that reason.

Wintertime data from the Surface Heat Budget of the Arctic Ocean (SHEBA) Experiment (e.g., Perovich et al. 1999; Uttal et al. 2002) are used because it is the only overice, in situ data set sufficiently complete for such an analysis. Detailed evolution of the interactions during Jan. 1-12, 1998, are examined, and the relationships found during this period are studied for the entire SHEBA winter. Even though the SHEBA data were collected over multi-year ice more than 18 years ago and the "new Arctic" resulting from recent changes consists primarily of first-year ice, many of the processes acting during the SHEBA winter likely 
represent current processes of importance, though their frequency and magnitudes may have changed.

Section 2 briefly describes the data used for this analysis. Section 3 provides a description of the large-scale evolution and the moisture plumes being studied. Section 4 shows impacts on cloud microphysics and surface energy fluxes, focusing on several process relationships and dependencies. Section 5 examines the impacts of these events on sea ice thermal and thickness evolution. A discussion and concluding remarks are provided in Sect. 6.

\section{Observational data used}

The near-surface atmospheric, snow, and ice observations used are the composited SHEBA hourly measurements created and used by Persson (2012). These measurements use observations from several measurement sites available at SHEBA, based on the quality of that data and whether data gaps existed. The primary source of the meteorological and surface energy budget (SEB) data is the Atmospheric Surface Flux Group (ASFG) data set (Persson et al. 2002), while measurements from the sites run by the SHEBA Project Office, Atmospheric Radiation Measurement program, and the National Center for Atmospheric Research are used to supplement this data. This data set is complete and provides direct observations of all terms of the surface energy budget of the multi-year SHEBA site:

$F_{\text {net }}=F_{a t m}+F_{c}$

$=\mathrm{R}_{\text {net }}-\mathrm{H}_{\text {turb }}-\mathrm{SW}_{\mathrm{t}}+\mathrm{F}_{\mathrm{c}}$

$=\mathrm{LW}_{\mathrm{d}}-\mathrm{LW}_{\mathrm{u}}+\mathrm{SW}_{\mathrm{d}}-\mathrm{SW}_{\mathrm{u}}-\mathrm{H}_{\mathrm{s}}-\mathrm{H}_{\mathrm{l}}-\mathrm{SW}_{\mathrm{t}}+\mathrm{F}_{\mathrm{c}}$

where $F_{n e t}$ is the net surface energy flux; $F_{a t m}\left(F_{c}\right)$ is the atmospheric energy flux (surface conductive energy flux), $\mathrm{R}_{\text {net }}$ the net radiative fluxes $\left(=\mathrm{LW}_{\mathrm{d}}-\mathrm{LW}_{\mathrm{u}}+\mathrm{SW}_{\mathrm{d}}-\mathrm{SW}_{\mathrm{u}}\right)$, LW (SW) represent the longwave (shortwave) downwelling (d) and upwelling ( $\mathrm{u}$ ) fluxes, $\mathrm{H}_{\text {turb }}$ is the sum of the turbulent sensible $\left(\mathrm{H}_{\mathrm{s}}\right)$ and latent $\left(\mathrm{H}_{\mathrm{l}}\right)$ heat fluxes; and $\mathrm{SW}_{\mathrm{t}}$ is the shortwave radiation transmitted through the ice. The four radiative flux terms are directly measured with radiometers, while the turbulent heat flux terms are measured with sonic anemometers and computed using the covariance technique. $F_{c}$ is computed using the measured surface and snow/ice interface temperatures and the measured snow depth at the ASFG site, as described by Persson et al. (2002) and Persson (2012). SW $\mathrm{SW}_{\mathrm{t}}$ is zero during the polar night period of concern in this study. Snow and ice characteristics are primarily obtained from measurements made by the Ice Physics Group (IPG; Perovich et al. 2002, 2003), and explained in more detail in Sect. 5. Data from only two IPG sites ("Pittsburgh" and "Quebec2") are used in this study, with Pittsburgh located $\sim 100 \mathrm{~m}$ from the ASFG flux tower and Quebec 2 about $1300 \mathrm{~m}$ distant. Figure 1 of Persson et al. (2002) and Fig. 2 of Perovich et al. (2003) show relative locations. Persson (2012) explains how these data sets are prioritized and combined into an improved and temporally more complete composite data set, and shows comparisons between similar variables to justify the necessary choices.

Other SHEBA observational data sets used in this study include the 2-4 times daily rawinsonde launches, and nearcontinuous measurements from a vertically pointing $8-\mathrm{mm}$ cloud radar (MMCR), lidar, ceilometer, and microwave radiometer (Intrieri et al. 2002; Uttal et al. 2002; Westwater et al. 2001). Cloud fraction, ice water path, and liquid water path are calculated from these multisensor data as described by Intrieri et al. (2002), Shupe et al. (2005, 2006) and Shupe (2007). Cloud fraction relies primarily on the lidar data and is computed temporally. Unless otherwise stated, hourly surface observations are used, including vertically integrated cloud parameters. National Centers for Environmental Prediction surface and $500 \mathrm{mb}$ analyses, and NOAA infrared satellite imagery were also used. Detailed descriptions of these and other SHEBA data sets, including the composited data used here, can be found at http://www.eol.ucar.edu/projects/sheba/. General descriptions of the SHEBA data collection effort are provided by Perovich et al. (1999) and Uttal et al. (2002), while details are given in Persson et al. (2002), Intrieri et al. (2002), Perovich et al. (2002, 2003), and Persson (2012).

\section{Large-scale evolution}

\subsection{Methodology}

The University of Alaska-Fairbanks collected a series of composite NOAA polar-orbiting infrared satellite images during the SHEBA year. These have a temporal resolution of a few hours or better, and have thus been examined for their ability to describe the synoptic evolution. Figure 1 shows a subsampled sequence of images from 0612 UTC Jan. 2 to 0528 UTC Jan. 4, 1998. The thermal signatures of the key features are subtle in these images, though, in general the following guidelines were used in this subjective analysis:

1. Dark regions (warm temperatures) represent relatively warm and moist air with primarily only low-level clouds,

2. Light regions showing wispy filaments represent highlevel clouds, and

3. Light regions with small-scale embedded dark spots represent the ice surface and hence clear sky condi- 



Fig. 1 Sequence of IR satellite images for Jan. 2-4, 1998 over the Arctic basin. The SHEBA location is shown by the red "x". The red lines outline regions of warm air, with the heavier red line outlining the warmest air. The annotated features are discussed in the text 
tions. The embedded dark spots during the clear skies represent spatial variations in ice and snow thickness, and hence in surface temperature (e.g., Overland et al. 2000; Persson et al. 2005).

The high temporal resolution of the images is key to discerning the temporal evolution of synoptic systems and our ability to identify and follow the main features. In Figs. 1, 2, 3 and 4, annotation is used to help identify the main features; this is especially useful since the images cannot be presented with the temporal resolution used in the analysis. Figures 5 and 6 show rawinsonde, radar, and surface observations from the SHEBA site; these are used to help interpret the satellite images.

\subsection{Interpretation of synoptic evolution}

Figure 1a shows a "stream" of higher clouds entering the Arctic Basin from east of Svalbard near 06 UTC Jan. 2 (YD367; in this study, day of year starts on Jan. 1, 1997), while clear skies and surface temperatures near $-40{ }^{\circ} \mathrm{C}$ dominate near the SHEBA site (red " $x$ " in Fig. 1; also see Fig. 5b). A warmer signature and lower-level clouds are seen around the periphery of these high clouds, and may also be present below them. This initial push of warm air and deep clouds deforms over the Beaufort Sea, but reaches the SHEBA site shortly after 20 UTC Jan. 2 (Fig. 1b, c). Warming at all levels above $300 \mathrm{~m}$ and the deeper clouds are seen in the SHEBA rawinsondes and radar reflectivity profiles, respectively (Fig. 6a). Also, a second flow of even warmer air is seen entering the Arctic basin through the Fram Strait shortly before 20 UTC Jan. 2 (Fig. 1b). This second push of warmer air (indicated by darker IR signature) and clouds reaches the SHEBA site near 00 UTC Jan. 4 (Figs. 1e, 6a). Frontal analysis using time-height sections of the equivalent potential temperature (not shown) and wind fields suggest that both of these streams of warm air represent two warm fronts located above the primary inversion, which itself is located between 100 and $900 \mathrm{~m}$ above the surface (Fig. 6a). The deeper clouds and very weak precipitation associated with the first warm front can be seen by the radar reflectivity near and shortly after 00 UTC Jan. 3 (YD368). The clouds above $2-3 \mathrm{~km}$ appear to be initiated by a region of potential instability above the warm front, as is common for fronts in mid-latitudes (e.g., Matejka et al. 1980), likely leading to the observed light surface precipitation. The second warm front is the leading edge of even warmer air with core temperatures near $-9^{\circ}$ to $-10^{\circ} \mathrm{C}$ (Fig. 6a) and relatively significant moisture (mixing ratio $\mathrm{q}_{\mathrm{v}} \sim 1-1.7 \mathrm{~g} \mathrm{~kg}^{-1}$ ) (Fig. 5a) in the 900-2500 $\mathrm{m}$ layer. The near-surface temperature gradually increases to $\sim-25^{\circ}$ to $-21{ }^{\circ} \mathrm{C}, 10-\mathrm{m}$ winds become westerly and increase to 6-9 $\mathrm{m} \mathrm{s}^{-1}$, and surface pressure falls (Fig. 5b-d). Above the inversion top, winds are northerly at the times of the warm frontal passages. After the passage of the first warm front and the associated area of potential instability, the clouds become shallow with tops near $800-1200 \mathrm{~m}$, which is typical for Arctic stratocumulus (Sc) clouds (e.g., Shupe et al. 2006).

Figure 1d (1613 UTC Jan. 3) also shows high clouds streaming northward from the Greenland coast with a cyclonic circulation. It is likely that this upper airflow is encountering vortex stretching in the lee of Greenland, enhancing its cyclonic vorticity. Note also that the air nearest the Canadian archipelago south of this warm air intrusion is clear, and that a small wave is forming along the cloud boundary. This may be a manifestation of downward penetration of the lee vortex in this upper-level flow. This upper-level circulation attains a larger diameter as its cloud edge moves across the Arctic Basin towards the Beaufort Sea, and the cloud-edge wave becomes a clear low-level circulation as well. These higher clouds leading this upperlevel circulation reach the SHEBA site near 00 UTC Jan. 5 above $4500 \mathrm{~m}$ (Figs. 2d, 5a, 6a), and the passage of the boundary presents itself as a weak cold front (Figs. 5a, 6a). The free-tropospheric winds above the inversion back to westerly before the passage of this cold front (see wind barbs in Figs. 5a, 6a), consistent with the growth of this vortex (e.g., see Fig. 2a-d). After the cold frontal passage, wind speeds decrease and veer to first northerly and then easterly. Thermal and moisture signatures do not show evidence of a frontal passage below about $1500 \mathrm{~m}$, though the wind direction shifts as far down as $1000 \mathrm{~m}$. Note that the air becomes drier between 1400 and $3000 \mathrm{~m}$ with this frontal passage (Fig. 5a).

The sequence of satellite images for Jan. 5 (Fig. 2d-f) shows the region of shallower moisture and the increasingly larger region of clear skies that eventually encompasses the SHEBA site. Movement of this drier air, and eventually clear skies, out over the Arctic Ocean from the Canadian Archipelago is consistent with easterly flow above the inversion and northerly to easterly flow near the surface (Fig. 5c). The radar shows that skies clear at the SHEBA site near 16 UTC Jan. 5, though the clouds became thinner at least $6 \mathrm{~h}$ earlier. A turbulent boundary layer with upward surface sensible heat flux was found up to 07 UTC, while high-frequency turbulence disappears and low-frequency turbulence appears near the surface after 15 UTC after a strong surface inversion of over $6{ }^{\circ} \mathrm{C}$ is established (T. Mauritsen-personal communication). High-frequency turbulence represents classical boundary-layer turbulence typically represented by Monin-Obhukov Similarity Theory, while lower frequency turbulence is believed to be more typical of very stable boundary layers and forced by larger-scale processes, such as gravity waves (see Grachev et al. 2005 for further discussion of this distinction for 

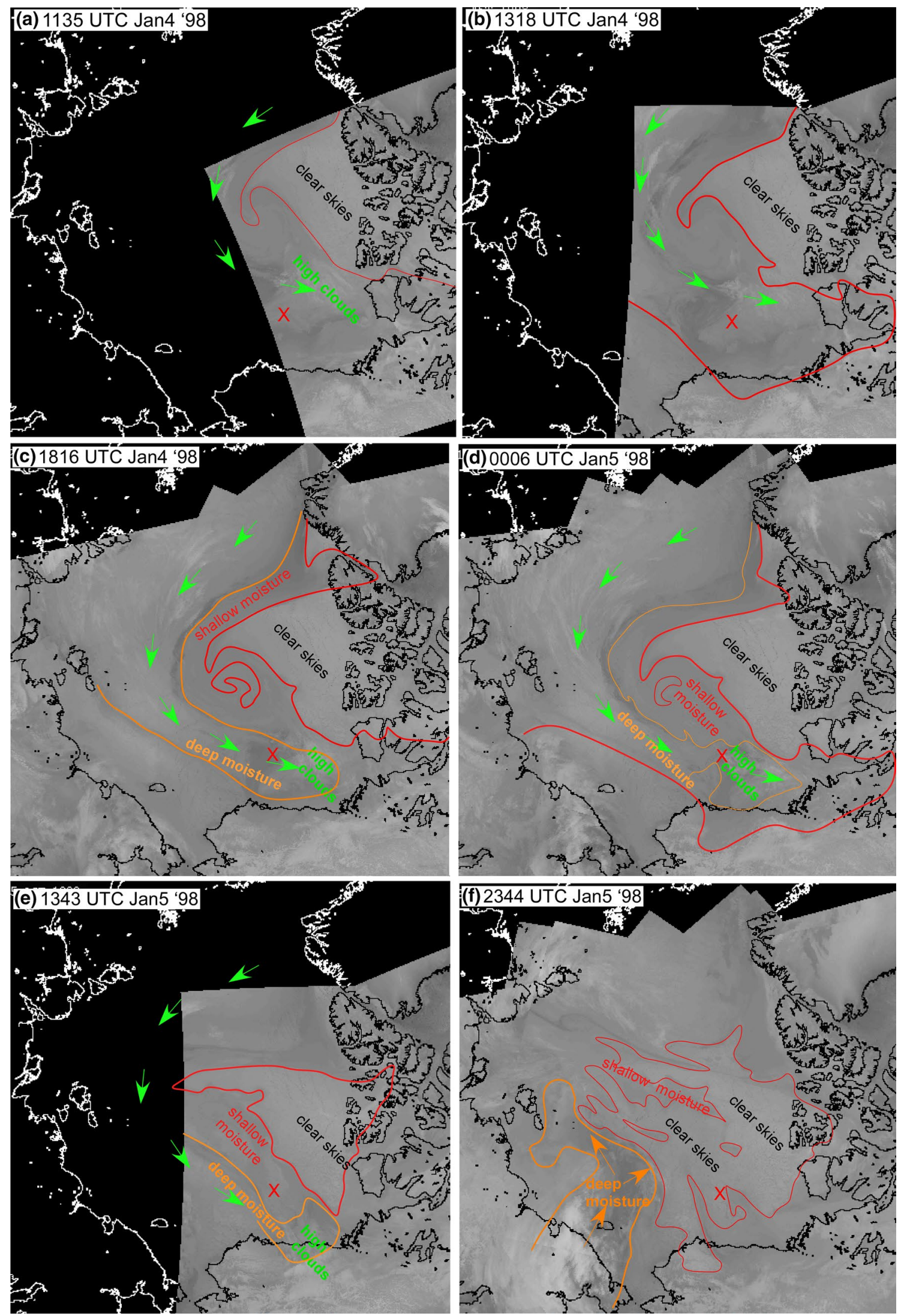

Fig. 2 As for Fig. 1, but for Jan. 4-5, 1998 



Fig. 3 As for Fig. 1, but for Jan. 5-7, 1998 




Fig. 4 As for Fig. 1, but for Jan. 8-11, 1998

the SHEBA data). This sequence of satellite images suggests that this moisture intrusion and its associated clouds did not dissipate and transform into the clear-sky state, as suggested by Pithan et al. (2014). Instead, it suggests that they were replaced by, and possibly mixed with, a drier air mass originating from the Canadian archipelago, with topographic forcing of the mesoscale eddy likely playing an important role. That is, advection is the dominant processes rather than air-mass transformation for producing the observed changes at the SHEBA site, as also suggested for other seasons by other studies (e.g., Mauritsen et al. 2011; Sedlar et al. 2011; Persson 2012).

The satellite image at 00 UTC Jan. 6 (Figs. 2f, 3a) shows these clear skies, and also shows the flow of warm air and low clouds over the Arctic Ocean in advance of deeper clouds from northeast Siberia. By 06 UTC Jan. 6, a circulation likely associated with a low-pressure system (marked by "L") is evident over Siberia, and the northward movement of warm/moist air continues. By 20 UTC Jan. 6 , the cloud structure suggests the presence of low pressure just north of the Siberian coast with likely a warm front and developing upper-level cold front to its northeast advancing eastward towards the SHEBA site. Deep clouds and light precipitation arrive at the SHEBA site near 08 UTC Jan. 7 (Fig. 5a). The decrease in temperature (Fig. 6a) suggests that this is a cold front, though the satellite image sequence (Fig. 3c-f) shows an advancing warm signature behind the brief cold upper clouds. The warm signature is due to the region of low-level clouds produced by the moisture increase behind this cold front (Fig. 5a).

It appears as if a mesoscale wave forms on this front and moves southward, producing the weak pressure minimum 


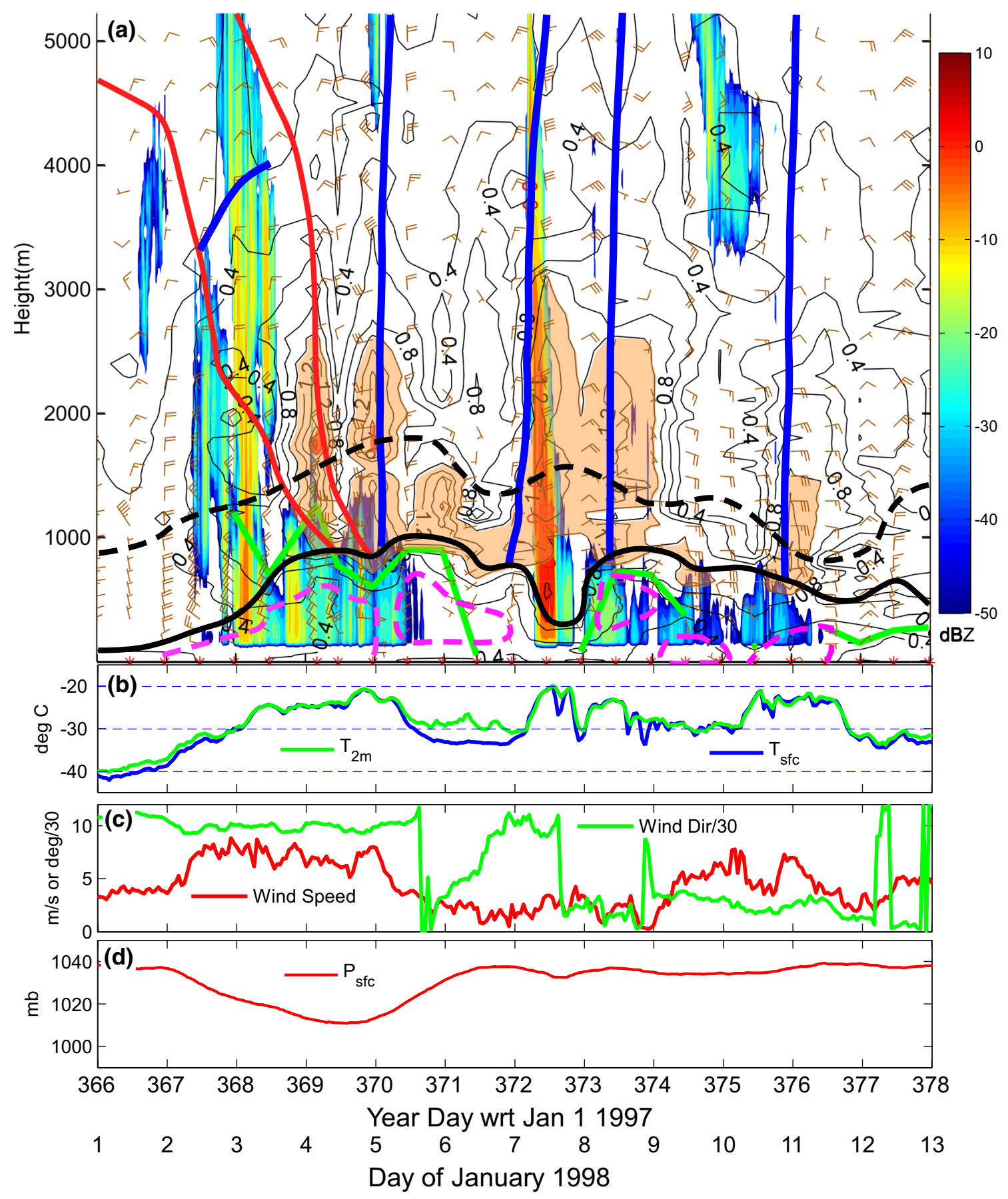

Fig. 5 Observations of the synoptic evolution in the lowest $5 \mathrm{~km}$ at the SHEBA site for Jan. 1-12, 1998. Shown are a time-height crosssection of mixing ratio $\left(\mathrm{g} \mathrm{kg}^{-1}\right.$; with tan shading $\left.>1 \mathrm{~g} \mathrm{~kg}^{-1}\right)$, wind barbs, and radar reflectivity (color; dBZ); b surface and 2-m air temperatures; c 10-m wind speed and direction; and d surface pressure. In a, cold and warm fronts, determined from wind and $\theta_{\mathrm{e}}$ fields (not shown), are given by heavy blue and red lines, respectively;

near 16 UTC Jan. 7 in Fig. 5d and leaving the SHEBA site on the irregular edge of the deeper moisture for the next $24 \mathrm{~h}$ (see Figs. 3f, 4a), after which the moisture above the heights of maximum relative humidity with respect to water $\left(\mathrm{RH}_{\mathrm{W}}\right)$ for RHw $>95 \%$ are linked by green lines; dashed magenta curves enclose regions of well-mixed air; the heavy black line shows the top of the strongest portion of the inversion; and the dashed black line shows the inversion top (height of the maximum temperature). The red stars along the time axis in a show times of the rawinsonde launches

inversion dissipates leaving much more tenuous clouds from 22 UTC Jan. 8 through 6 UTC Jan. 10. A few days earlier, another region of enhanced moisture and clouds 

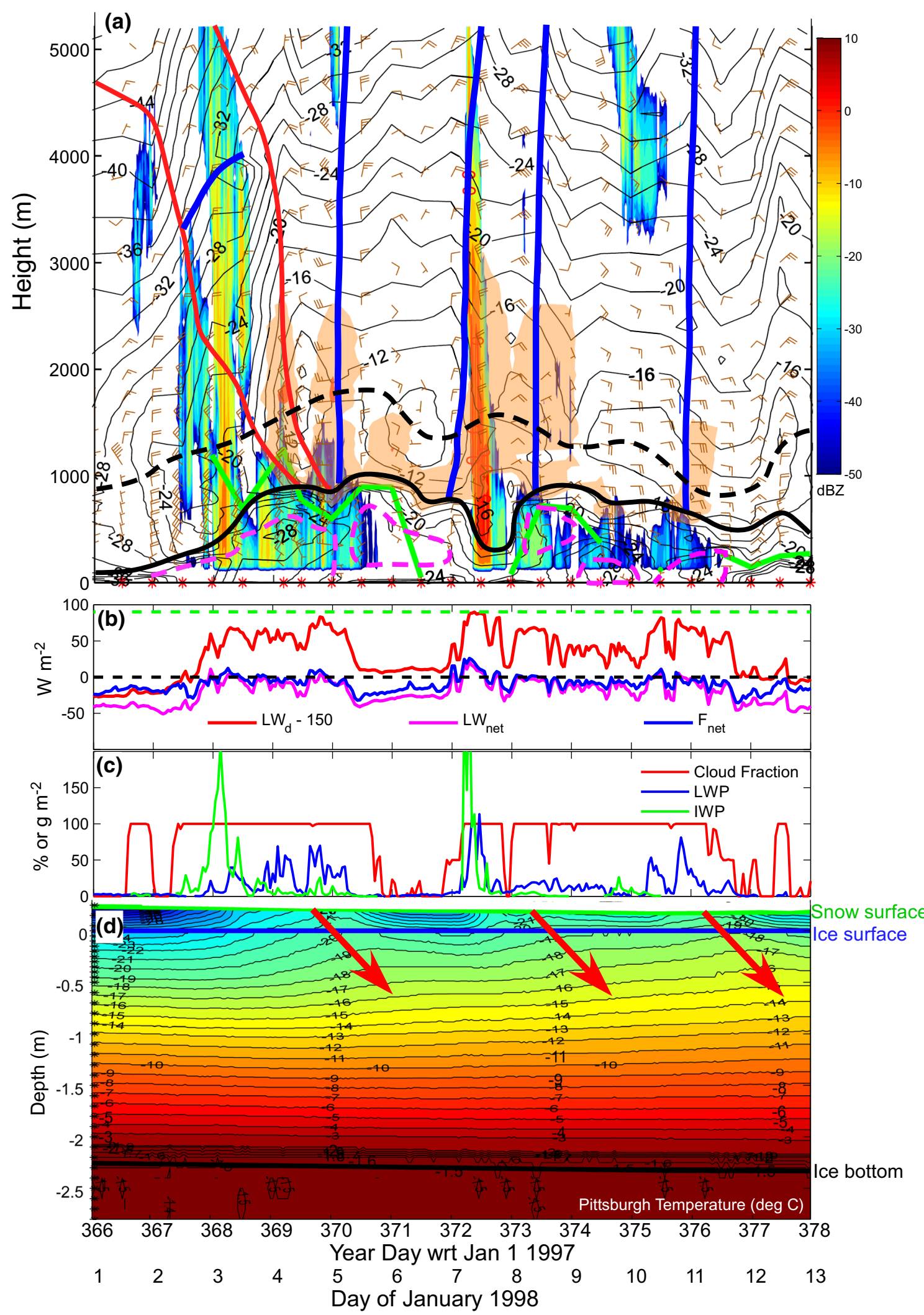

Fig. 6 As for Fig. 5, but showing a isotherms (black; ${ }^{\circ} \mathrm{C}$ ); b energy budget terms $\mathrm{LW}_{\mathrm{d}}$ (less $150 \mathrm{~W} \mathrm{~m}^{-2}$ ), $\mathrm{LW}_{\text {net }}$, and $\mathrm{F}_{\text {net }} ; \mathbf{c}$ cloud fraction (\%), liquid water path $\left(\mathrm{g} \mathrm{m}^{-2}\right)$ (LWP), and ice water path $\left(\mathrm{g} \mathrm{m}^{-2}\right)$ (IWP), and $\mathbf{d}$ isotherms in the surface snow and the sea ice $\left({ }^{\circ} \mathrm{C}\right)$. The dashed green line in $\mathbf{b}$ shows the radiative flux (less $150 \mathrm{~W} \mathrm{~m}^{-2}$ ) of a black body at $-18{ }^{\circ} \mathrm{C}$. The thermal waves in the snow and ice associated with the mixed-phase cloud events are shown by the red arrows 
enters the Arctic Basin through the Fram Strait and moves along the coastline of the Canadian archipelago, eventually extruding a filament of moisture and clouds across the Beaufort Sea (Fig. 4a-c) that enhances mid-level moisture and stratocumulus clouds below between 18 UTC Jan. 10 and 06 UTC Jan. 11 (Fig. 5a, b). After this time, midlevel winds gradually shift to northerly, absolute humidity decreases at all levels, and skies remain clear for several days in a band across the western hemisphere high Arctic (Figs. 4d, 5a). However, the temperature in the 1000 $2000 \mathrm{~m}$ layer warms slightly to $-12^{\circ} \mathrm{C}$ while the near surface temperature falls to below $-30^{\circ} \mathrm{C}$ (Figs. 5b, 6a).

Further evidence to support this general synoptic evolution is provided by ERA40 reanalysis data (Uppala et al. 2005). In the data-poor Arctic Ocean these reanalysis data are primarily dependent on satellite-derived observations to improve the model-generated first-guess fields. The ERA40 reanalysis (Fig. 7) shows the penetration of synoptic moisture plumes into the Arctic Basin, supporting the above observational analysis. A circulation north of Greenland on the moisture plume entering through the Fram Strait is also present as in the satellite images (e.g., Figure 7c, d). The SHEBA sounding data, which was assimilated by ERA40, will most likely only have impacted the immediate vicinity of the SHEBA site and down-wind of it in these analyses. Furthermore, this reanalysis has been shown to produce reasonable basic meteorological parameters (e.g., surface pressure) and statistics of vertical thermal structure in the Arctic (e.g., Tjernström and Graversen 2009; Walsh et al. 2009).

In summary, two warm fronts and a series of cold fronts move across the SHEBA site during the first 12 days of January, 1998. One of the warm fronts and one of the cold fronts produce enough mid-tropospheric instability and lifting to generate deeper clouds and light precipitation for a few hours each at the SHEBA site. The two warm fronts enter the Arctic Basin near Svalbard, the cold front generating precipitation is associated with a low-pressure system entering from northeast Siberia, and the other fronts are associated with features originating along the north coast of Greenland or the Canadian archipelago. The warm and moist air behind the second warm front passing the SHEBA site appears to enter the Arctic Basin through the Fram Strait, as does a brief period of moisture behind the last cold-frontal feature. The moisture plume behind the precipitating cold front enters the Arctic Basin from the northern Pacific Ocean across northeastern Siberia. Shallow stratocumulus clouds have their tops in the moisture plumes, which occur in the 1000-2000 m layer behind several of the frontal passages. Other frontal passages initiate drying aloft. Lateral mixing between moist and dry plumes may have been produced by mesoscale eddies, leading to dissipation of clouds in the moist plumes. Relatively warm surface temperatures occur during cloudy periods, regardless of whether they are stratocumulus clouds or deeper precipitating clouds associated with deep baroclinicity. Nearsurface winds and surface pressure are also modulated by the frontal passages aloft. The next section will more carefully characterize the two kinds of clouds and the observed relationships between the clouds and surface energy fluxes.

\section{Observed surface energy budget dependencies}

Cloud fraction (CF), ice water path (IWP), and liquid water path (LWP) are shown in Fig. 6c. Cloud fraction is generally near $100 \%$ when any type of cloud is present. Figure $6 \mathrm{c}$ shows that these remote sensing instruments identify a cloud even if it is quite tenuous and only consists of ice (e.g., the cloud at $2500-4000 \mathrm{~m}$ between 14 and 23 UTC Jan. 1). The two periods of deeper frontal clouds and precipitation are characterized by significant $\operatorname{IWP}\left(>150 \mathrm{~g} \mathrm{~m}^{-2}\right)$ and low-to-modest LWP $\left(5-50 \mathrm{~g} \mathrm{~m}^{-2}\right)$. The shallow stratocumulus clouds show generally small $\operatorname{IWP}\left(<20 \mathrm{~g} \mathrm{~m}^{-2}\right)$ and modest LWP $\left(10-100 \mathrm{~g} \mathrm{~m}^{-2}\right)$. There are even some periods when the stratocumulus clouds are almost entirely composed of supercooled liquid water (e.g., 06 UTC Jan. 10-18 UTC Jan. 11). The cloud-phase mask determined by combining data from several of the SHEBA remote sensors (Fig. 8), as described by Shupe (2007) and Shupe et al. (2011), shows that the liquid areas occur primarily at the tops of the Sc clouds, with mixed-phase or all ice occurring at lower levels in Sc clouds or throughout most of the deeper clouds at the frontal passages.

Previous studies have linked Arctic clouds to surface warming in non-summer months (e.g., Persson et al. 1999; Shupe and Intrieri 2004; Stramler et al. 2011). Comparing Fig. $6 \mathrm{~b}, \mathrm{c}$ shows that the $\mathrm{LW}_{\mathrm{d}}$ is enhanced by $60-100 \mathrm{~W} \mathrm{~m}^{-2}$ during the cloudy periods compared to clear ones. A closer examination, however, suggests that this correlation is much better using the LWP (or IWP + LWP) rather than the $\mathrm{CF}$, as $\mathrm{CF}$ easily reaches $100 \%$ for even small LWP or IWP.

The net atmospheric energy flux $\left(\mathrm{F}_{\text {net }}\right)$ at the surface of the snow on top of the sea ice is $\sim-30$ to $-10 \mathrm{~W} \mathrm{~m}^{-2}$ during clear periods and generally between -10 and $+10 \mathrm{~W} \mathrm{~m}^{-2}$ during cloudy periods (Fig. $6 \mathrm{~b}$ ), with one peak to $+20 \mathrm{~W} \mathrm{~m}^{-2}$. These values represent the residuals resulting from the net longwave radiative flux $\left(\mathrm{LW}_{\text {net }}\right)$ loss (note that both SW terms are zero during this polar night period) and generally gains through $\mathrm{H}_{\text {turb }}$ and $\mathrm{F}_{\mathrm{c}}$. The compensating effects of $\mathrm{H}_{\text {turb }}$ (which almost entirely consists of sensible heat flux $\mathrm{H}_{\mathrm{s}}$ ) and $\mathrm{F}_{\mathrm{c}}$ are shown in Fig. $9 \mathrm{~b}$. $\mathrm{H}_{\text {turb }}$ can at times be slightly positive (cooling the surface) during cloudy periods.

The following relationships suggested by this case will be explored quantitatively below using a longer SHEBA 


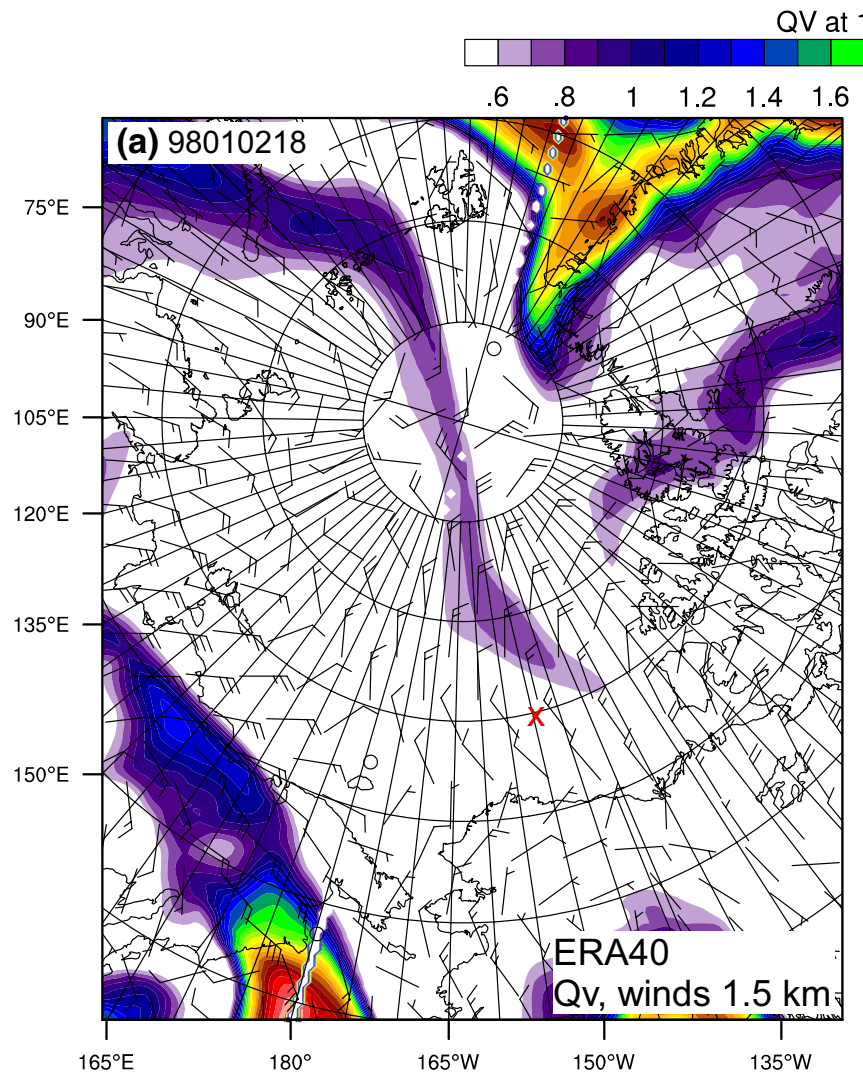

at $1.5 \mathrm{~km}(\mathrm{~g} / \mathrm{kg})$
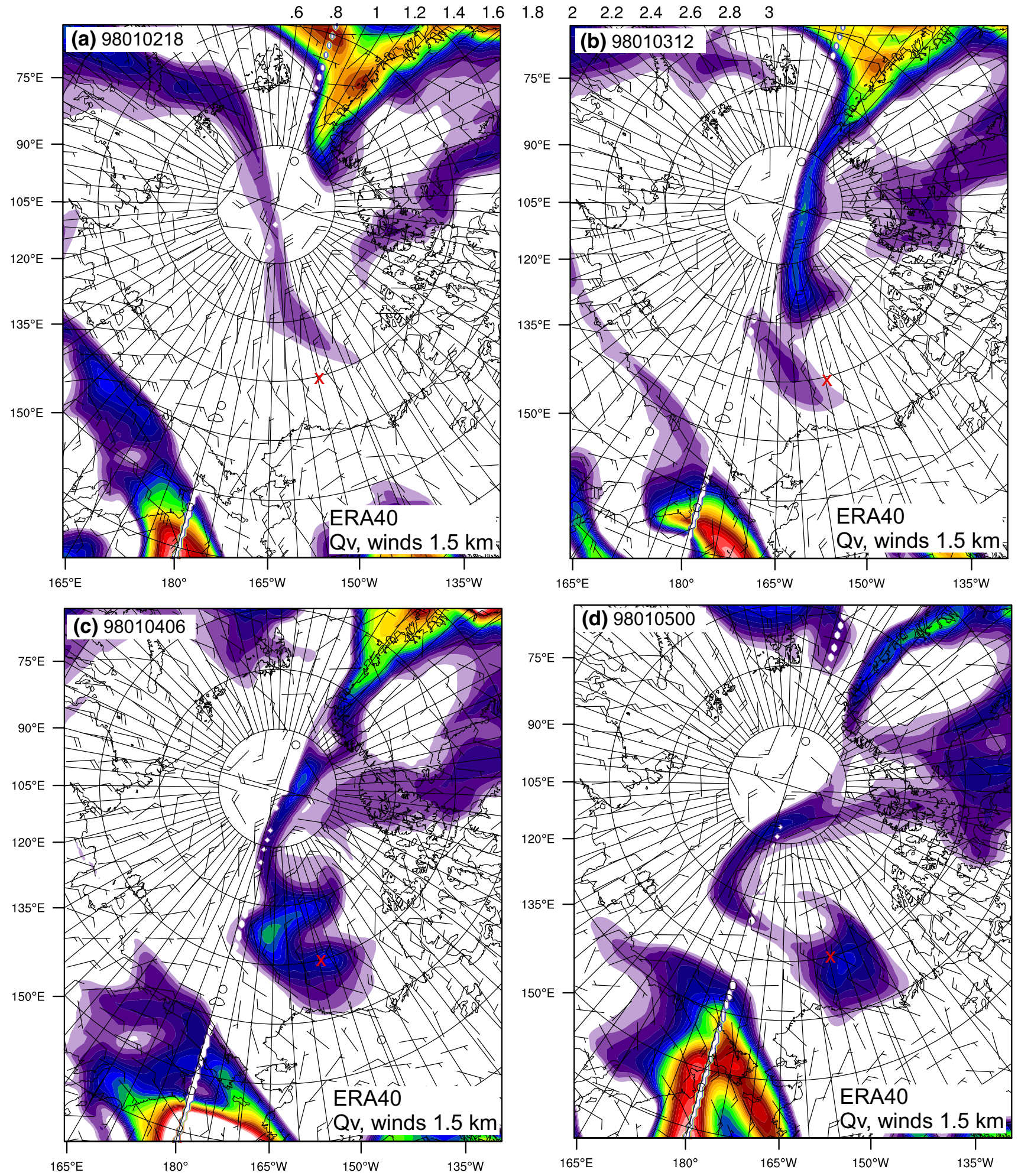

Fig. 7 Water vapor mixing ratio (color) and wind barbs at $1.5 \mathrm{~km}$ altitude in ERA40 from Jan. 218 UTC through Jan. 5, 199800 UTC over the Arctic Ocean. The red " $x$ " marks the SHEBA location 
Fig. 8 As for Fig. 6a, but showing the cloud-phase mask determined from the cloud radar, microwave radiometer, cloud lidar, and rawinsondes as done by Shupe (2007) and Shupe et al. (2011). The red $x$ 's denote the lowest height of the air temperature corresponding to the surface longwave radiative temperature


Fig. 9 Time series of observed surface energy budget terms at SHEBA for Jan. 1-12, 1998. The black dashed lines show the zero value period: (a) water vapor mixing ratio in the 1000-2000 m layer and stratocumulus cloud characteristics; (b) $\mathrm{LW}_{\mathrm{d}}$ and CF, IWP, and LWP; (c) dependence of the relationships between $\mathrm{LW}_{\mathrm{d}}, \mathrm{H}_{\text {turb }}$, and $\mathrm{F}_{\mathrm{C}}$ on cloud characteristics; and (d) dependence of the relationship between $\mathrm{H}_{\mathrm{s}}$ and $\Delta \mathrm{T}$ on cloud characteristics. $\Delta \mathrm{T}$ is the air-surface temperature difference in the lowest $10 \mathrm{~m}$. The first relationship is examined because Fig. 5a suggests that the Sc clouds may be deeper and penetrate further into the inversion at times of enhanced mid-level water vapor (e.g., at YD369.2 and YD370.0) and vice versa for times of less water vapor. This could potentially impact the resulting LWP. Identifying moisture plume characteristics that may impact cloud characteristics and subsequent surface radiation is of importance, and would be a unique contribution.

\subsection{Water vapor mixing ratio (1000-2000 m layer) vs stratocumulus cloud characteristics}

To examine relationships between moisture amounts near the tops of Sc clouds and cloud characteristics, the mean mixing ratio $\left(\mathrm{Q}_{\mathrm{V}}\right)$ in the 1000-1500 $\mathrm{m}$ layer $\left(\mathrm{Q}_{\mathrm{v}_{-} 1000 \_1500}\right)$ and in the $500 \mathrm{~m}$ just above the tops of the low clouds $\left(Q_{V_{-} 500}\right)$ were both computed. Low clouds are defined as those with tops below $1800 \mathrm{~m} . \mathrm{Q}_{\mathrm{v}_{-} 1000 \_1500}$ used only the sounding data, while $\mathrm{Q}_{\mathrm{v}_{-} 500}$ also required the radar-determined cloud top height. To increase the number of points, SHEBA observational data from Dec. 1, 1997 through Feb. 28, 1998 are used. The top row of Fig. 10 shows the LWP and the IWP as a function of the 1000-1500 m mixing ratio. The scatter for both parameters is fairly large, though there is a suggestion that a LWP $<10 \mathrm{~g} \mathrm{~m}^{-2}$ (dashed line) occurs only for $Q_{v_{-} 1000 \_1500}<1 \mathrm{~g} \mathrm{~m}^{-2}$. Higher values of $\mathrm{Q}_{\mathrm{v} \_1000 \_1500}$ always produce higher values of LWP. However, some values of LWP $>10 \mathrm{~g} \mathrm{~m}^{-2}$ occur for very low $Q_{V_{-} 1000 \_1500}$. No obvious relationship is evident between $\mathrm{Q}_{\mathrm{v}_{-} 1000 \_1500}$ and IWP. When using $\mathrm{Q}_{\mathrm{v}_{5} 500}$ to examine only cases when clouds are present, the above relationships become clearer though fewer data points are available. Figure 10c shows that a $\mathrm{Q}_{\mathrm{v} \_500}>1 \mathrm{~g} \mathrm{~kg}^{-1}$ was always associated with significant LWP $\left(>10 \mathrm{~g} \mathrm{~m}^{-2}\right)$, while low LWP $\left(<10 \mathrm{~g} \mathrm{~m}^{-2}\right)$ occurs only for $\mathrm{Q}_{\mathrm{V}_{\_} 500}<1 \mathrm{~g} \mathrm{~kg}^{-1}$. As before, however, high LWP can occur for $Q_{v_{-} 500}<1 \mathrm{~g} \mathrm{~kg}^{-1}$, so factors other than available water vapor apparently are also important for determining the LWP. These factors may include cloud condensation and ice nuclei concentrations, which were not measured. 

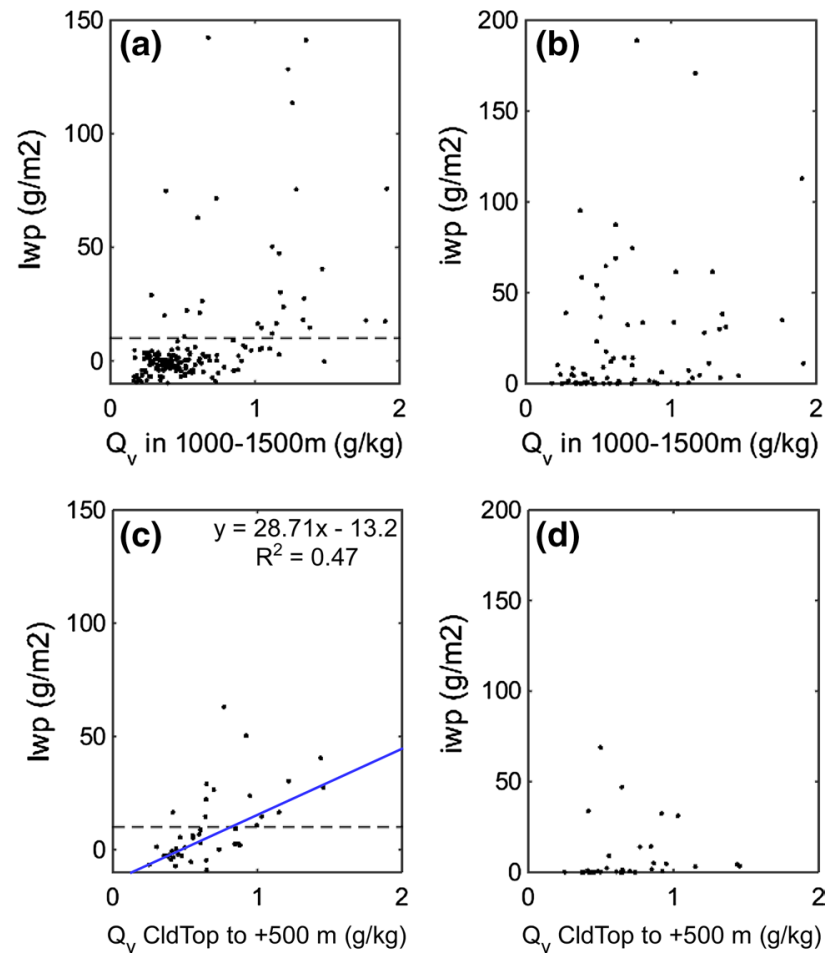

Fig. 10 Link between $\mathrm{Q}_{\mathrm{v}}$ in height layers 1000-1500 m (top row) or cloud top to $+500 \mathrm{~m}$ (bottom row) and LWP $\left(\mathrm{g} \mathrm{m}^{-2}\right)$ (first column) and IWP $\left(\mathrm{g} \mathrm{m}^{-2}\right)$ (second column). The maximum cloud top height considered was $1800 \mathrm{~m}$. The data is for SHEBA for Dec. 1, 1997Feb. 28, 1998. The top row includes all soundings $(\mathrm{n}=176$ for $\mathbf{a}$; $\mathrm{n}=80$ for $\mathbf{b}$ ), while the bottom row includes only points for soundings with low clouds $(n=43)$. A blue regression line is only shown for the one panel demonstrating any correlation, with the indicated correlation coefficient and regression line

Though a water vapor threshold for producing cloud liquid water makes physical sense, the theoretical uncertainty in the LWP measurements is $\sim 25 \mathrm{~g} \mathrm{~m}^{-2}$ (Westwater et al. 2001), so we can only be certain that cloud liquid water exists above this value. However, the responses in longwave radiation shown in the next subsection have convinced us that the actual uncertainty in the data used is between 5 and $10 \mathrm{~g} \mathrm{~m}^{-2}$. Hence, the $10 \mathrm{~g} \mathrm{~m}^{-2}$ threshold is used for defining significant LWP.

\section{2 $\mathrm{LW}_{\mathrm{d}}$ versus CF, IWP, and LWP}

Downwelling longwave radiation is a key component of the Arctic surface energy budget, especially during winter. As seen in Figs. $6 \mathrm{~b}$ and $9 \mathrm{~b}, \mathrm{LW}_{\mathrm{d}}$ varies significantly during the study time period, frequently displaying sudden increases or decreases of $60-80 \mathrm{~W} \mathrm{~m}^{-2}$ or more. Previous studies have suggested that these variations are due to cloud phase (e.g., Persson et al. 1999; Shupe and Intrieri 2004; Stramler et al. 2011, Mauritsen et al. 2011; Sedlar et al. 2011; Persson 2012), while additional factors include cloud temperature and cloud optical depth (Shupe and Intrieri 2004). Figure 11a shows the observed $L_{d}$ as a function of the observed water path (WP $=$ LWP + IWP) at SHEBA for December through February. Clearly, the smallest $\mathrm{LW}_{\mathrm{d}}\left(\sim 120-140 \mathrm{~W} \mathrm{~m}^{-2}\right)$ occur for $\mathrm{WP}<5 \mathrm{~g} \mathrm{~m}^{-2}$, and an upper threshold occurs near $235 \mathrm{~W} \mathrm{~m}^{-2}$ once WP exceeds $30-40 \mathrm{~g} \mathrm{~m}^{-2}$. If the data set is reduced by including only hours that have exclusively liquid or ice clouds, we see that $L_{\mathrm{d}}$ is much more sensitive to the LWP than it is to the IWP (Fig. 11b). $\mathrm{LW}_{\mathrm{d}}$ saturates at a LWP value of about $35 \mathrm{~g} \mathrm{~m}^{-2}$, while it approaches saturation at an IWP of $100-150 \mathrm{~g} \mathrm{~m}^{-2}$. There is also much greater scatter for the $\mathrm{LW}_{\mathrm{d}}$ impact of ice-only clouds than for the liquid-only clouds, probably partially due to the more widely varying heights (and temperatures) of ice clouds and the relatively consistent low-level heights (warm temperatures) of liquid clouds. Some ice-only points may also contain some liquid water, considering the uncertainty of the LWP measurements. However, Fig. 11b shows that, for a given amount

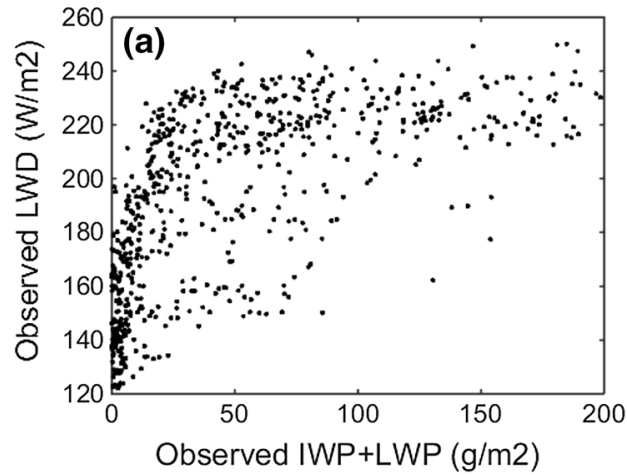

Fig. 11 Correlations between cloud characteristics (LWP, IWP) and $\mathrm{LW}_{\mathrm{d}}$ for Dec. 1, 1997, through Feb. 28, 1998, at SHEBA. Panel a shows the observed $\mathrm{LW}_{\mathrm{d}}$ as a function of the total cloud water content (IWP+LWP), and $\mathbf{b}$ shows $\mathrm{LW}_{\mathrm{d}}$ as a function of LWP and IWP sepa-

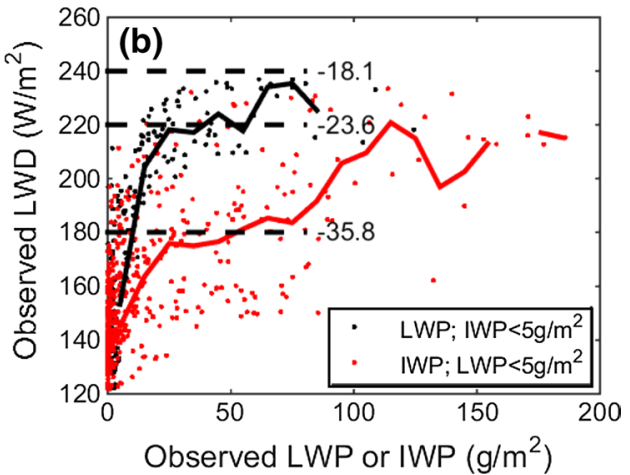

rately. In b only LWP (IWP) points are shown for which IWP (LWP) $<5 \mathrm{~g} \mathrm{~m}^{-2}$. Also in $\mathbf{b}$ the dashed lines show the blackbody temperatures corresponding to the $\mathrm{LW}_{\mathrm{d}}$ values 
of water, liquid water typically has a much stronger impact on $\mathrm{LW}_{\mathrm{d}}$ than does ice. For reference, blackbody equivalent temperatures are marked for a few $\mathrm{LW}_{\mathrm{d}}$ values in Fig. 11b; it can be seen that the upper limit to $\mathrm{LW}_{\mathrm{d}}$ corresponds to a blackbody temperature of about $-20{ }^{\circ} \mathrm{C}$.

To better visualize what atmospheric layers primarily contribute to each hourly value of $\mathrm{LW}_{\mathrm{d}}$, the lowest level with a temperature corresponding to the blackbody radiative temperature of each hourly $\mathrm{LW}_{\mathrm{d}}$ is marked by a red " $\mathrm{x}$ " on the cloud-phase mask cross section (Fig. 8). For the first Sc cloud period (YD368.5-370.7), many of the hours correspond to a radiative level near the base of the liquid layer or within the mixed-phase layer, near the $-20{ }^{\circ} \mathrm{C}$ isotherm. These are likely the times of optically thick Sc clouds. A few hours for this first Sc period and most hours during the second Sc period (YD372.8-376.3) are optically thin and hence have significant contributions from both the relatively warm cloud layer below and from colder air at higher levels. The resulting radiative temperatures correspond to colder temperatures only found above the center of the mid-level warm air. Note that this does not mean that the radiative height is at this upper-level height (which is often without clouds), but only that a significant contribution comes from levels higher than the low-level clouds. Note also that the $\mathrm{LW}_{\mathrm{d}}$ increase (and the surface radiative temperature) could have been much greater if optically thick clouds had occurred within the core of the warm/moist air near $1.5 \mathrm{~km}$ height and not below. Because the Sc clouds form only on the lower boundary of this intrusion of warm/ moist air, the radiative impact is "only" $60-100 \mathrm{~W} \mathrm{~m}^{-2}$.

Figure $6 \mathrm{a}$ shows that the stratocumulus clouds, as defined by the reflectivity field, extend hundreds of meters above the tops of the mixed layers (magenta areas in Fig. 6a), which classically correspond to the tops of the Arctic stratocumulus clouds and the base of the overlying inversion (e.g., Solomon et al. 2011). Sometimes, such as on Jan. 3 and 4, clouds extend through the strongest portion of the inversion and penetrate well into the base of the moisture plume. This cloud penetration of up to $600 \mathrm{~m}$ above the inversion base is greater than that more generally observed (e.g., Sedlar et al. 2012). However, since radiative emission heights for optically thick clouds (Fig. 8) are located near the base of the liquid cloud and the inversion, it appears that these cloud penetrations into the inversion have little radiative effect, at least for the optically thick clouds.

\subsection{Dependence of $L W_{d}$ versus $H_{t u r b}$ and $F_{c}$ on cloud characteristics}

Process relationships reveal how a physical system responds to changes in forcing. For instance, based on the SEB Eq. (1c), changes in $\mathrm{LW}_{\mathrm{d}}$ would be expected to produce changes in other energy fluxes, such as $\mathrm{LW}_{\mathrm{u}}, \mathrm{H}_{\mathrm{s}}$, and/or $\mathrm{F}_{\mathrm{c}}$ during the Arctic night (solar radiation and $\mathrm{H}_{1}$ are essentially zero at this time). This is because a change in $\mathrm{LW}_{\mathrm{d}}$ alters the SEB balance, thereby changing $T_{s}$ and hence affecting these other fluxes (Persson 2012). Figure 12a shows a scatterplot of SHEBA wintertime observations of $\mathrm{H}_{\text {turb }}\left(\mathrm{H}_{\mathrm{s}}+\mathrm{H}_{1}\right)$ and $F_{c}$ as a function of $L_{\text {net }}\left(\mathrm{LW}_{\mathrm{d}}-\mathrm{LW}_{\mathrm{u}}\right)$. By using $\mathrm{LW}_{\text {net }}$ as the forcing parameter, the radiative response to the change in $\mathrm{LW}_{\mathrm{d}}$ and the surface temperature change is incorporated into the forcing term. Clearly, $\mathrm{LW}_{\text {net }}$ has a bimodal distribution, with one peak near $-40 \mathrm{~W} \mathrm{~m}^{-2}$ and the other near $0 \mathrm{~W} \mathrm{~m}^{-2}$, as noted by Persson et al. (1999). When $\mathrm{LW}_{\text {net }}$ is largely negative $\left(-40 \mathrm{~W} \mathrm{~m}^{-2}\right)$ the turbulent heat flux attempts to warm the surface by $5-20 \mathrm{~W} \mathrm{~m}^{-2}$ (average of $11.4 \mathrm{~W} \mathrm{~m}^{-2}$ ) and the conductive flux tries to warm it by $10-14 \mathrm{~W} \mathrm{~m}^{-2}$ (average of $11.6 \mathrm{~W} \mathrm{~m}^{-2}$ ). When $\mathrm{LW}_{\text {net }}$ is approximately in balance $\left(\mathrm{LW}_{\text {net }} \sim 0 \mathrm{~W} \mathrm{~m}^{-2}\right)$, the surface is warmed slightly $\left(\sim 5.0 \mathrm{~W} \mathrm{~m}^{-2}\right)$ by the conductive heat flux but cooled slightly $\left(\sim 2.3 \mathrm{~W} \mathrm{~m}^{-2}\right)$ by the turbulent heat flux. Hence, the magnitude and even sign of $\mathrm{H}_{\text {turb }}$ and $\mathrm{F}_{\mathrm{c}}$ are primarily determined by the $\mathrm{LW}_{\text {net }}$ regime. Additional analysis shows that this bimodal distribution occurs with $\mathrm{LW}_{\mathrm{d}}$ as well, thereby indicating that the primary forcing during the polar night is from the downwelling longwave radiation. In Fig. 12b, the hourly data points have been classified by the magnitude of the LWP, with a LWP $<5 \mathrm{~g} \mathrm{~m}^{-2}$ being classified as "dry" and LWP $>10 \mathrm{~g} \mathrm{~m}^{-2}$ as "wet". This figure clearly shows that all points for which $\mathrm{LW}_{\text {net }}<-20 \mathrm{~W} \mathrm{~m}^{-2}$ are "dry", which means that they represent conditions of either clear skies or ice-only clouds, and that all "wet" clouds have a $\mathrm{LW}_{\text {net }}$ close to $0 \mathrm{~W} \mathrm{~m}^{-2}$. Hence, the liquidwater content of the clouds not only strongly influences the $\mathrm{LW}_{\mathrm{d}}$, but also force the responses of the turbulent and conductive heat fluxes.

\subsection{Dependence of $H_{s}$ versus $\Delta T$ on cloud characteristics}

The response of $\mathrm{H}_{\text {turb }}$ to changes in $\mathrm{LW}_{\text {net }}$ (and $\mathrm{LW}_{\mathrm{d}}$ ) in the previous section is implied to be due to changes in surface temperature $\left(\mathrm{T}_{\mathrm{s}}\right)$, but other parameters such as the surfacelayer stability and the bulk-flux transfer coefficient will also change. These parameters are related by the bulk flux equation for sensible heat, $\mathrm{H}_{\mathrm{s}}$, which is:

$\mathrm{H}_{\mathrm{S}}=-\rho \mathrm{C}_{\mathrm{H}} \mathrm{U}_{10}\left(\mathrm{~T}_{10}-\mathrm{T}_{\mathrm{S}}\right)$,

where $\mathrm{C}_{\mathrm{H}}$ is the bulk transfer coefficient, $\mathrm{T}_{10}$ and $\mathrm{U}_{10}$ are the temperature and wind speed at $10 \mathrm{~m}$ height, and $\rho$ is the air density. After rearranging, $\mathrm{C}_{\mathrm{H}}$ can be seen to be directly proportional to the ratio between the wind-normalized sensible heat flux $\left(\mathrm{H}_{\mathrm{s}} / \mathrm{U}_{10}\right)$ and stability $\left(\Delta \mathrm{T}=\mathrm{T}_{10}-\mathrm{T}_{\mathrm{s}}\right)$ via

$\mathrm{C}_{\mathrm{H}}=-(1 / \rho)\left(\mathrm{H}_{\mathrm{s}} / \mathrm{U}_{10}\right) /\left(\mathrm{T}_{10}-\mathrm{T}_{\mathrm{s}}\right)$. 
Fig. 12 Summarizing the importance of LWP for process relationships relating longwave radiation and turbulent sensible heat flux $\left(\mathrm{H}_{\text {turb }}\right)$ and conductive flux $\left(\mathrm{F}_{\mathrm{C}}\right)(\mathbf{a}, \mathbf{b})$, and the nearsurface stability and the windnormalized turbulent sensible heat flux (heat transfer coefficient) (c, d). For $\mathbf{b}, \mathbf{d}$, the cloud liquid conditions are defined by (dry: LWP $<5 \mathrm{~g} \mathrm{~m}^{-2}$; wet: LWP $>10 \mathrm{~g} \mathrm{~m}^{-2}$ ). Mean values of $\mathrm{H}_{\text {turb }}$ (red) and $\mathrm{F}_{\mathrm{C}}$ (blue) are shown for $\mathrm{LW}_{\text {net }}$ ranges of -50 to $-30 \mathrm{~W} \mathrm{~m}^{-2}$ and -10 to $+10 \mathrm{~W} \mathrm{~m}^{-2}$, respectively, in a. Bin-averaged values are shown in green in c. Data from Dec. 1, 1997, through Feb. 28, 1998 are used
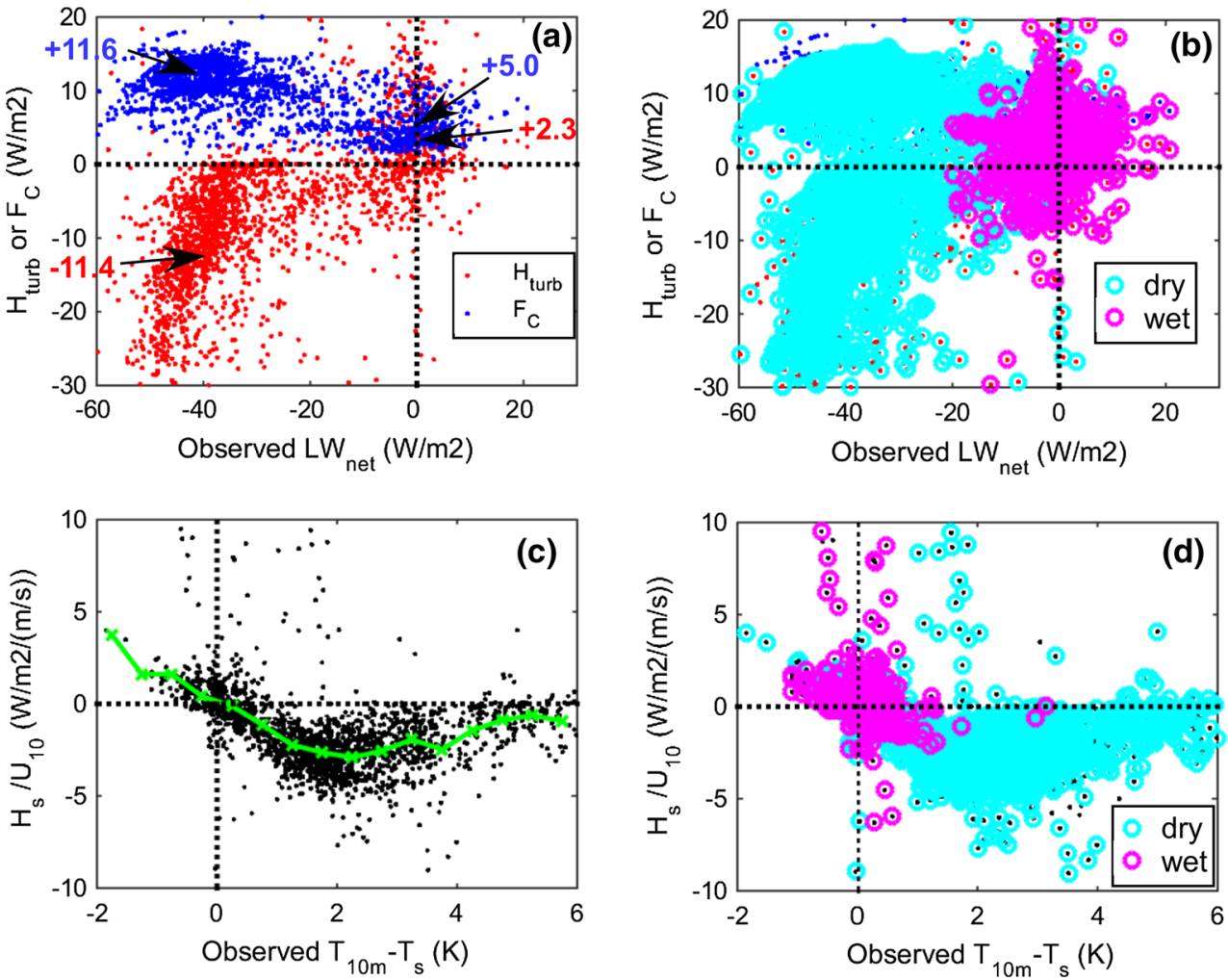

Figure $12 \mathrm{c}$ shows hourly values of observed $\mathrm{H}_{\mathrm{s}} / \mathrm{U}_{10}$ as a function of observed $T_{10}-T_{s}$ for the SHEBA winter months. As stability increases with cooling $\mathrm{T}_{\mathrm{s}}$ or warming $\mathrm{T}_{10}, \mathrm{H}_{\mathrm{s}}$ changes sign and becomes increasingly negative until the temperature difference reaches about $2 \mathrm{~K}$. In this near-neutral or weakly stable portion of the plot, the heat transfer coefficient is approximately constant (i.e., the slopes of lines from each point through the origin are approximately constant). However, as the surface cooling (10-m warming) continues and low-level stability increases further, the increased stability begins to limit turbulence and thereby reduces the magnitude of $\mathrm{C}_{\mathrm{H}}$ and $\mathrm{H}_{\mathrm{s}}$. This portion of the plot represents very stable conditions (e.g., Grachev et al. 2005). If again each point is classified according to its associated LWP (Fig. 12d), it becomes clear that the near-surface atmospheric system is in the near-neutral regime where $\mathrm{C}_{\mathrm{H}}$ is approximately constant when significant cloud liquid water exists. When no significant cloud liquid water exists, it is typically in the stable or very stable regime where $\Delta T>1$. That is, the phase of the clouds produce the stability impact, not just the existence of clouds. Grachev et al. (2007) discuss the values of $\mathrm{C}_{\mathrm{H}}$ implied by the slopes in Fig. $12 \mathrm{c}$ and compare them to other studies. Tjernström et al. (2005) show that only few surface-layer schemes are able to reproduce the functional relationship shown by Fig. 12c.

These examples of observed process relationships illustrate the significance of the presence of cloud liquid water to the quantitative functioning of the cloud-atmospheric boundary layer-surface system. If, for instance, a model is unable to reproduce appropriate amounts of cloud liquid water, not only will the magnitudes of the radiative fluxes be in error, but other dependent processes such as turbulent and conductive heat fluxes will likely also be in error. In some cases, the lack of a response from dependent processes produces errors that compensate for the initial error in the forcing fluxes (e.g., $\mathrm{LW}_{\mathrm{d}}$ ), thereby leading to impacts on some parameters (e.g., $\mathrm{T}_{\mathrm{s}}$ ) that may not be as bad as if the original error were acting alone. For example, if a modeled cloud lacked the supercooled liquid water, the $\mathrm{LW}_{\mathrm{d}}$ would be too small, leading to a too low $\mathrm{T}_{\mathrm{s}}$. However, the $\mathrm{H}_{\text {turb }}$ and $\mathrm{F}_{\mathrm{c}}$ would heat the surface more than they would have if $\mathrm{T}_{\mathrm{s}}$ had increased, thereby warming the surface somewhat and reducing the magnitude of the $\mathrm{T}_{\mathrm{s}}$ error produced by the lack of liquid clouds.

\section{Observed impacts on sea-ice temperature and growth}

Figure $6 \mathrm{~d}$ shows that the surface heating by liquid-containing clouds produces a thermal wave that penetrates through the snow cover and into the interior of the sea ice. The impacts of these thermal waves on the sea-ice temperature, internal conductive heat flux, and bottom ice growth are explored in this section. 
(a)

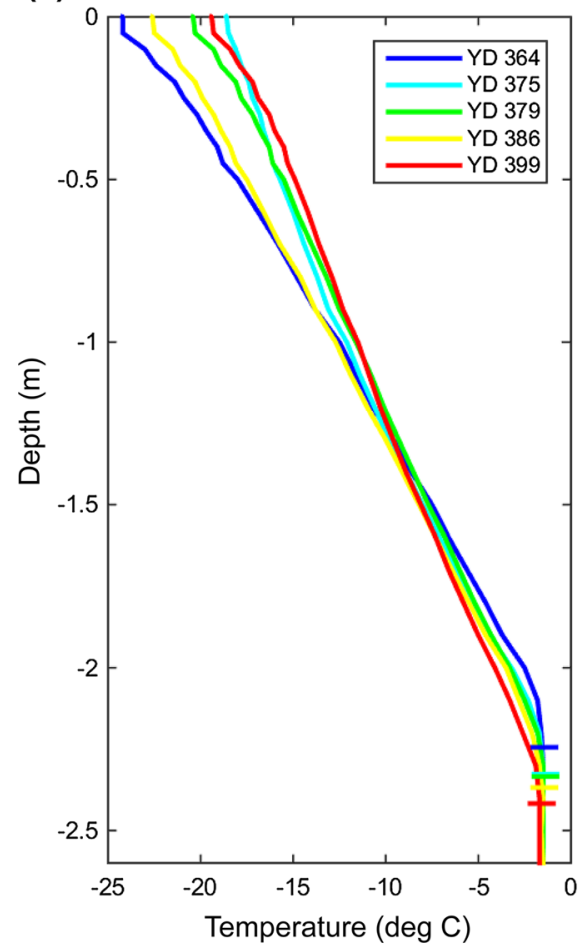

(b)
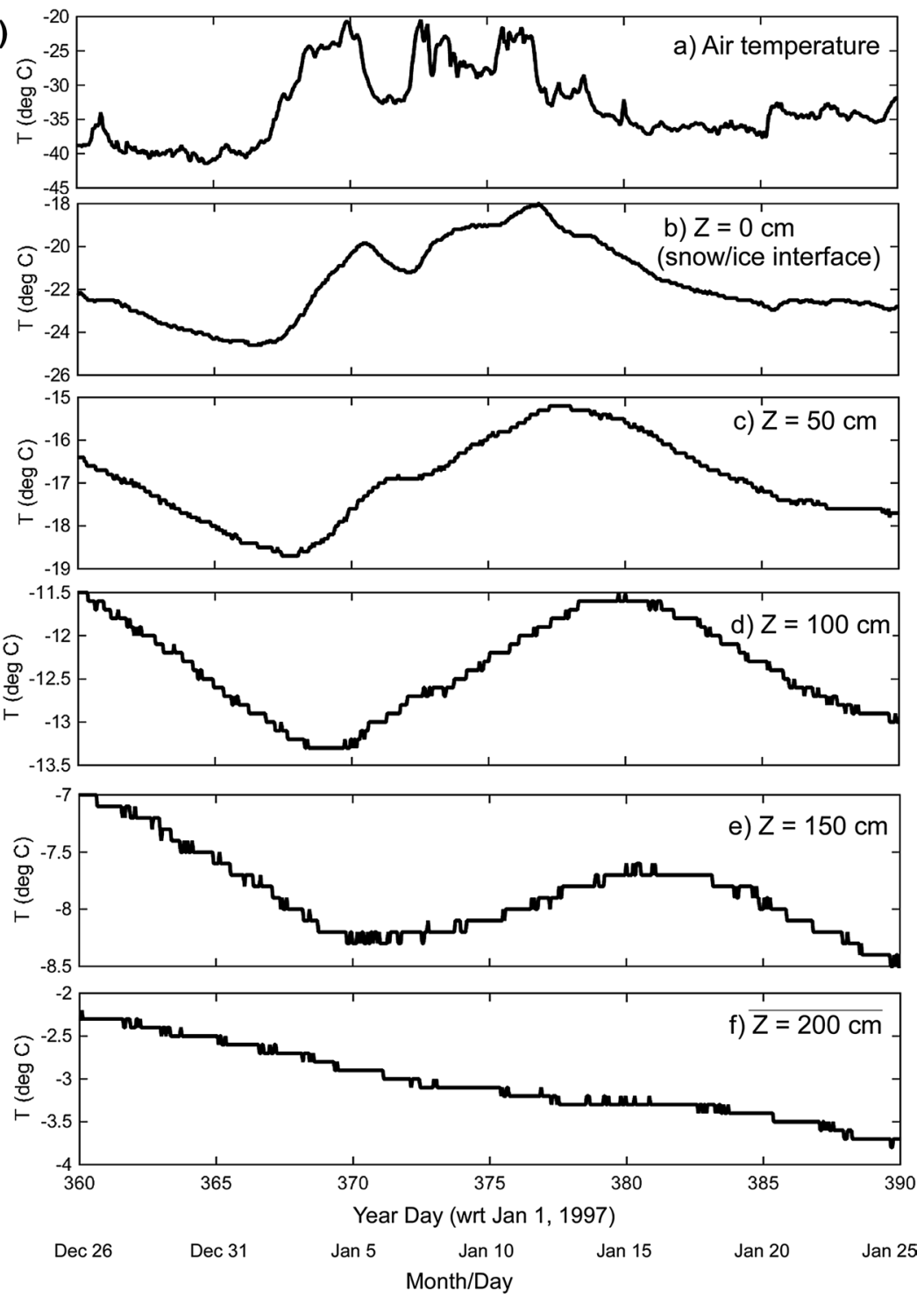

Fig. 13 a Ice temperature as a function of depth at the Pittsburgh site at 21 UTC for select midwinter days (YD = Year Day wrt Jan. 1, 1997) when ice thickness measurements were made. The horizontal bars correspond to the ice bottom at the time of the temperature pro- file of the same color. b Observed time series of air temperature (a) and of ice temperature from thermistors located at ice depths of $(b)$ $0 \mathrm{~cm},(c) 50 \mathrm{~cm},(d) 100 \mathrm{~cm},(e) 150 \mathrm{~cm}$, and $(f) 200 \mathrm{~cm}$
Figure 13a shows several ice temperature profiles from the thermistor string at the "Pittsburgh" (PITT) site coincident with ice thickness measurements at this site between Dec. 30, 1997, and Feb. 3, 1998 (e.g., Perovich et al. 2003). Thermistors were located between $50 \mathrm{~cm}$ above the snowice interface to about $3 \mathrm{~m}$ below it, with spacing every $5 \mathrm{~cm}$ from $5 \mathrm{~cm}$ above the snow-ice interface to $50 \mathrm{~cm}$ below it and every $10 \mathrm{~cm}$ elsewhere. In midwinter, three thickness gauges were located at the Pittsburgh site within a few meters of each other, with the ice-bottom depth shown in Fig. 13a being the mean of these three. The range of the three thicknesses was $52 \mathrm{~cm}$ on Nov. 17, decreasing to $38 \mathrm{~cm}$ by Feb. 27, with two of them being within $5-10 \mathrm{~cm}$ of each other, and the third showing significantly thinner ice. Hence, the thinnest measurement is $30-35 \mathrm{~cm}$ less than the mean, while the thickest measurement is $10-15 \mathrm{~cm}$ greater. The temporal evolution of the variability is consistent with more rapid ice growth for thinner ice, while the spatial variability is indicative of highly variable bottom topography. The exact ice thickness at the Pittsburgh thermistor string is unknown; we assume that its thickness is represented by the mean of the three thickness gauges.

The ice temperature profiles in Fig. 13a show an approximately constant temperature gradient from just below the ice surface to $20-30 \mathrm{~cm}$ above the mean ice bottom. In the 20-30 $\mathrm{cm}$ above the ice bottom, the temperature gradient 
decreases rapidly, reaching isothermal conditions near the bottom. Significant temporal variability occurs in the top meter of ice. Steady cooling with time occurs in the $50 \mathrm{~cm}$ just above the ice bottom (e.g., at $2 \mathrm{~m}$ depth). This latter effect is due to the increasing distance between a constant depth and the growing ice bottom in conjunction with the constant bottom temperature (at the freezing point) and approximately constant temperature gradient.

Figure 13b shows the temperature evolution at 6 levels at Pittsburgh for about 1 month encompassing the earlyJanuary period of interest. It shows the $\sim 20 \mathrm{~K}$ increases in air temperature associated with the episodes of enhanced surface $F_{\text {atm }}$ due to the liquid clouds. Figures $6 \mathrm{~d}$ and $13 \mathrm{~b}$ show a $\sim 1.8{ }^{\circ} \mathrm{C}$ warming during this 12 -day period at $1-\mathrm{m}$ depth, which appears to be the integrated effect of the three thermal waves. Clearly, the pulse of warming is seen down to at least $150 \mathrm{~cm}$ depth with a 5-6 day time lag. At $200 \mathrm{~cm}$ depth, however, warming is not evident, though the rate of cooling mentioned previously decreases. This cooling at a constant depth near the ice bottom is a manifestation of the growth of ice at the bottom, and occurs independent of thermal waves produced by atmospheric events above. Hence, while warming is the more obvious effect of the thermal wave, the change in the rate of this cooling is also an indicator that the thermal wave has reached at least the $200 \mathrm{~cm}$ depth.

The temperature profiles and time series in Fig. 13 illustrate that the thermal waves are evident within the ice both as warming events and as changes in the vertical temperature gradients. The former suggests that energy storage within the ice from wintertime atmospheric events such as these may impact the amount of heat necessary in the spring and early summer to bring the sea-ice to its melting point. The latter directly impacts the conductive heat flux within the ice, and the rate of heat transport from the bottom to the surface of the ice. Hence, both effects are significant for the seasonal evolution of the ice.

The hourly temperature profiles from the thermistor strings can be used to calculate the heat conduction within the ice, $\mathrm{C}$, at a thermistor level $\mathrm{n}$ by applying the equation

$C_{n}=k_{n}\left(T_{n+1}-T_{n-1}\right) /\left(z_{n+1}-z_{n-1}\right)$,

where $\mathrm{k}$ is the thermal conductivity of ice, $\mathrm{T}$ is the temperature, and $\mathrm{z}$ is the depth. $\mathrm{k}$ is generally assumed to be $\sim 2 \mathrm{~W} \mathrm{~m}^{-1} \mathrm{~K}^{-1}$ for sea ice. Some research has suggested that the value may be as low as $1 \mathrm{~W} \mathrm{~m}^{-1} \mathrm{~K}^{-1}$ in the top $0.5 \mathrm{~m}$ of ice and potentially approaching $3 \mathrm{~W} \mathrm{~m}^{-1} \mathrm{~K}^{-1}$ near the bottom (Trodahl et al. 2001), though the near-surface reduction has been suggested to be an artifact by later studies (Pringle et al. 2006). Observed densities in the abovefreeboard part of ice cores are less than the lower portion of the cores, consistent with lower $\mathrm{k}$ near the surface; the near-bottom increase is thought due to brine conduction. In this study, thermal gradients tend to be stronger in the top $0.5 \mathrm{~m}$, suggesting that thermal conductivity is lower (maintaining approximately constant heat conduction). Hence, $\mathrm{k}$ is linearly decreased from 2 to $1 \mathrm{~W} \mathrm{~m}^{-1} \mathrm{~K}^{-1}$ between $0.5 \mathrm{~m}$ depth and the ice surface. No changes were made near the ice bottom. The assumption of a lowered near-surface $\mathrm{k}$ has no significance for this study, as the magnitudes of $\mathrm{C}$ near the ice surface are not primary. The thermistors located above the ice-snow interface and within the snowpack are used to calculate the near-surface conductive flux at Pittsburgh, similar to that done for measurements at the ASFG tower site $100 \mathrm{~m}$ distant (see Sect. 2). A thermal conductivity of $0.3 \mathrm{~W} \mathrm{~m}^{-1} \mathrm{~K}^{-1}$ (Sturm et al. 2002) was used for the snow layer. A three-point vertical smoother and a 72-h running mean are applied for spatial and temporal smoothing.

The time-depth cross-section from mid-November to the end of February obtained by applying Eq. (4) to the SHEBA Pittsburgh hourly thermistor temperature profiles is shown in Fig. 14. Clearly, pulses of enhanced or suppressed thermal conduction propagate from the surface towards the bottom of the ice, reaching the bottom of the quasi-constant temperature gradient and the top of the layer with decreasing thermal gradient $30-40 \mathrm{~cm}$ above the mean sea-ice bottom (solid red line). The liquid cloud events of Jan. 3-5 (YD368-370) and Jan. 7-11 (YD372376) (marked by brackets) are seen as two pulses of suppressed $\mathrm{C}$ that become one broader pulse dominated by the latter longer event near $1.2 \mathrm{~m}$ depth, and that reaches near the lowest $30-40 \mathrm{~cm}$ of the sea ice centered on Jan. 18 (YD383), 9 days later. Similar long-lived cloud/surface warming events in late November (YD324-331) and late January into early February (YD390-402) produced suppressed $\mathrm{C}$ pulses reaching to near the bottom of the sea ice 8 and 12 days later, respectively. Shorter lived events produce pulses that decay between 0.5 and $1.5 \mathrm{~m}$ depths. Atmospheric conditions with no liquid clouds produce pulses of enhanced $\mathrm{C}$, with again the longer-lived ones reaching depths near the ice bottom. The one from YD358366 is strongest, but others occur before and after. The bottoms of these longer-lived, deeper-penetrating pulses are approximately at the depth of the ice bottom of the thickness gauge in the thinnest ice at PITT. The zone of strong gradient in $\mathrm{C}$ near the base of these pulses in the $\sim 30 \mathrm{~cm}$ just above the ice bottom is subtly compressed (relaxed) for the pulses of enhanced (decreased) $\mathrm{C}$, suggesting a direct connection even to the mean sea-ice bottom.

Not only is the penetration depth governed by the timescale of the forcing event, but the amplitudes of the pulses decrease the further into the ice the pulse propagates. These characteristics are all consistent with known behavior of heat flow into soil by oscillatory heating pulses, such as the diurnal and annual cycles (e.g., Sellers 1974). However, in this case the heating pulses are produced by synoptic 
Fig. 14 Time-depth cross-section of conductive flux $\left(\mathrm{W} \mathrm{m}^{-2}\right)$ at the Pittsburgh site at SHEBA calculated from the hourly thermistor temperature profiles. The heavy red line shows the bottom of the ice as measured directly every 4-15 days; the dashed red line shows the ice bottom estimated from the hourly temperature profiles as described in the text. The dashed blue line is referenced in the text and is $50 \mathrm{~cm}$ above the solid red line. The solid green line shows the top of the snow at this site, while the dashed black line shows the snow-ice interface



atmospheric events and the associated cloud microphysical properties, and the behavior of the thermal pulses within the ice are complicated by the different boundary conditions, such as the increasing ice thickness, the fixed bottom temperature, and the bottom heat source from the latent heat of fusion (e.g., Stefan 1889; Wettlaufer 2001).

For ice to freeze on the bottom of sea ice, conductive heat flux, in turn dependent on $\mathrm{T}_{\mathrm{s}}$ and heat loss to the atmosphere, is necessary to remove the released latent heat of fusion. Hence, the conductive heat flux near the bottom of the ice $\left(C_{b}\right)$ forces the ice formation. Assuming the water at the ice bottom is at its freezing point, the rate of bottom ice formation $\mathrm{h}_{\mathrm{frz}}$ is given by

$\mathrm{h}_{\mathrm{frz}}=\left(\mathrm{C}_{\mathrm{b}}-\mathrm{F}_{\mathrm{O}}\right) /\left(\mathrm{L}_{\mathrm{f}} \times \rho_{\text {ice }}\right)$.

where $\rho_{\text {ice }}$ is the local ice density, $\mathrm{L}_{\mathrm{f}}$ is the latent heat of fusion, and $\mathrm{F}_{\mathrm{O}}$ is the ocean heat flux. Before January 24 (YD389), $\mathrm{F}_{\mathrm{O}}$ was found to be very small $\left(<2 \mathrm{~W} \mathrm{~m}^{-2}\right.$ ) (Perovich and Elder 2002; Shaw et al. 2009). Between January 24 and the end of February, three 1-3 day long episodes of enhanced $\mathrm{F}_{\mathrm{O}}$ produced mean $\mathrm{F}_{\mathrm{O}}$ of $\sim 3-4 \mathrm{~W} \mathrm{~m}^{-2}$. Since these values are significantly less than $\mathrm{C}_{\mathrm{b}}$, especially for the early January time period, $\mathrm{F}_{\mathrm{O}}$ is neglected in our computations but is considered in the interpretation of the results. Because (5) is to be applied for the freezing of sea water and the bottom of the sea ice likely consists of a mixture of new ice and brine pockets, the effective $L_{f}$ and $\rho_{\text {ice }}$ are both lower than their freshwater and pure ice values, respectively. Hence, we will use slightly lowered values of $\mathrm{L}_{\mathrm{f}}=3.0 \times 10^{5} \mathrm{~J} \mathrm{~kg}^{-1}$ and $\rho_{\text {ice }}=900 \mathrm{~kg} \mathrm{~m}^{-3}$. The values for $\mathrm{C}_{\mathrm{b}}$ used are those $50 \mathrm{~cm}$ above the mean ice bottom (dashed blue line in Fig. 14). These are shown in Fig. 15d, and labeled as "Near-bottom." The ice growth rates from (5) are shown in Fig. 15e. These vary between 3.8 and $6.8 \mathrm{~mm} /$ day, with an average of $5.5 \mathrm{~mm} /$ day. The difference between the peak near YD371 and the local minimum near YD382 is $1.2 \mathrm{~mm} /$ day, which is the estimated impact of the atmospheric synoptic/microphysical forcing of the surface temperature on the ice growth rate at the bottom of the ice. Episodes of positive $\mathrm{F}_{\mathrm{O}}$ after YD389 could reduce the ice growth rate to values smaller than those shown to result from only the surface-forced $\mathrm{C}_{\mathrm{b}}$.

Perovich et al. (2003) show direct measurements of ice growth rates for the many ice thickness gauges available at SHEBA and for different ice types (their Fig. 8). The average growth rates for the multi-year ice sites in late December and early January are 3-7 mm/day. Figure $15 \mathrm{f}$ shows the growth rates calculated from these thickness gauge data but for the two multi-year sites nearest the ASFG radiation and turbulent flux towers (Pittsburgh and Quebec2). The time series show the ice growth rates to vary between about 2-9 $\mathrm{mm}$ /day from mid-November to the end of February, with an average growth rate of 4.2 and $5.1 \mathrm{~mm} /$ day at PIT and QUB, respectively. These curves suggest a growth rate reduction of $4-5 \mathrm{~mm} /$ day due to the impact of the atmospheric synoptic/microphysical events on Jan. 3-12 

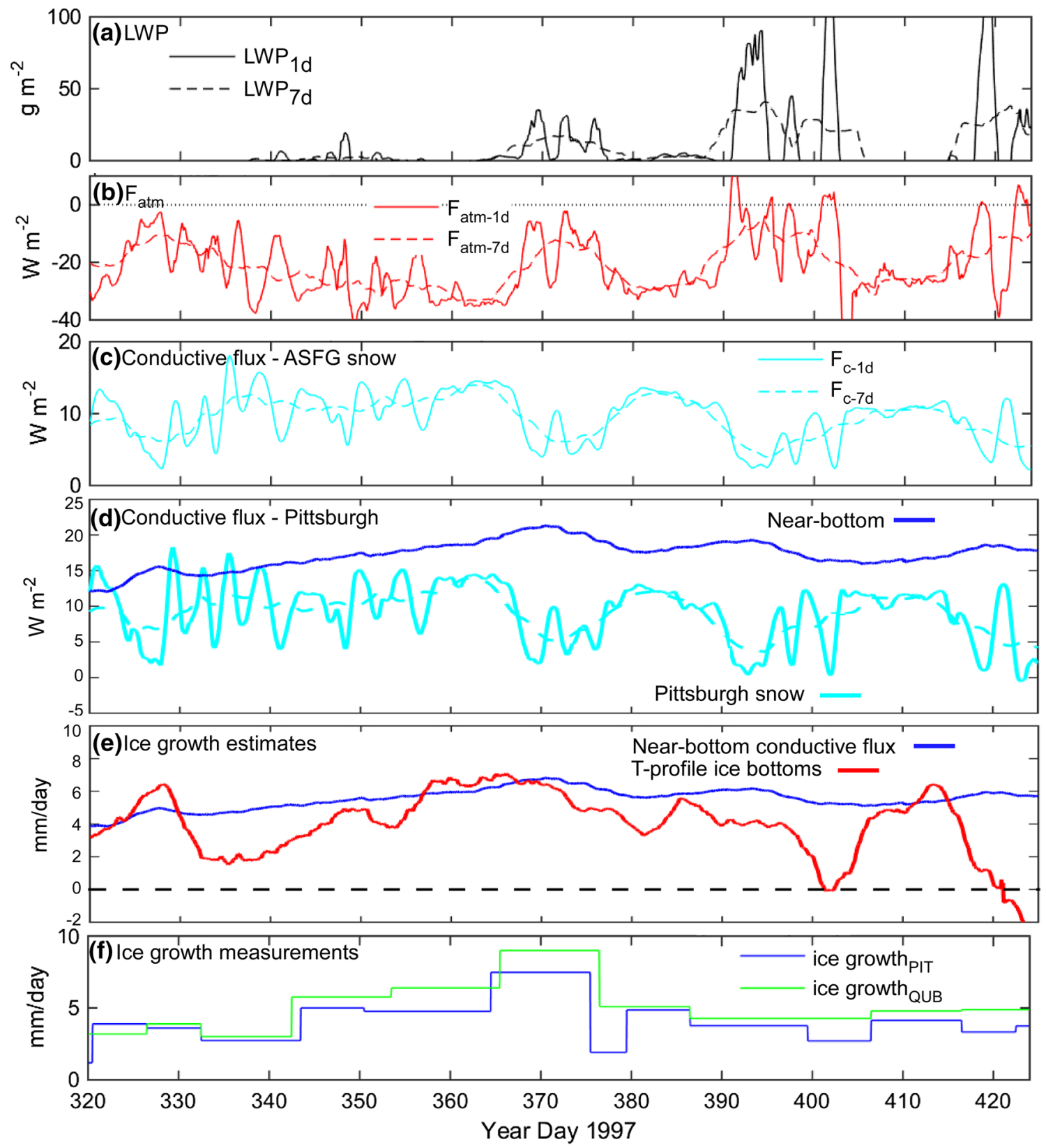

Nov 16 Nov 26 Dec $6 \quad$ Dec $16 \quad$ Dec $26 \quad$ Jan $5 \quad$ Jan $15 \quad$ Jan $25 \quad$ Feb $4 \quad$ Feb 14 Feb 24

Dates 1997-1998

Fig. 15 Time series of observed a LWP (black), b surface $\mathrm{F}_{\mathrm{atm}}$ (red), c $\mathrm{F}_{\mathrm{c}}, \mathbf{d}$ conductive flux at the Pittsburgh location in the surface snow (cyan) and near the ice bottom (blue), e ice growth estimates from the near-bottom conductive flux (blue) and the ice bottoms estimated from the hourly temperature profiles (red), and $\mathbf{f}$ measured basal ice growth rates at the nearest sites [Pittsburgh (blue); Quebec (green)] during SHEBA for Nov. 15, 1997-Feb. 28, 1998. In a-d solid lines show 24-h running means while dashed lines show 7-day running means

$\mathrm{F}_{\mathrm{c}}, \mathrm{F}_{\mathrm{atm}}$, or LWP. In an attempt to estimate the location of the sea-ice bottom from each individual hourly temperature profile, a 5-th order polynomial was fit to the bottom portion of the temperature profile and the first depth at which the temperature became nearly isothermal $\left(\partial \mathrm{T} / \partial \mathrm{z}<1.5^{\circ} \mathrm{C} / \mathrm{m}\right.$ ) was defined as the ice bottom (refer 
to Fig. 13a). Temporal smoothing of the resulting thicknesses was performed with a $96-\mathrm{h}$ running mean, producing a thickness time series which agrees well with measured ice thicknesses (see red dashed line in Fig. 14). The technique produces slowly varying seasonal biases which are removed with a linear detrending. The growth rate was then calculated using every other hour, and this ice growth rate was also smoothed with a 96-h running mean. The linear detrending and running mean provide a band-pass filter for the growth rates. The ice bottoms and growth rates found in this manner are referred to as "T-profile" bottoms and growth rates. The T-profile ice growth rates vary between -1 and $7.1 \mathrm{~mm} /$ day, with a mean of $4.2 \mathrm{~mm} /$ day (Fig. 15e). Hence, these growth rates show much greater variability than was found for the growth rates calculated from $\mathrm{C}_{\mathrm{b}}$, and comparable variability to those from the thickness gauge measurements.

Comparing the surface conductive fluxes (Fig. 15c, d) with the various estimates of bottom ice growth (Fig. 15e, $\mathrm{f}$ ), some correlation is evident, after accounting for a time lag (the phasing seems to be slightly earlier for the T-profile growth rates than seen in the $\mathrm{C}_{\mathrm{b}}$ growth rates). The growth rate difference of $\sim 3.2 \mathrm{~mm} /$ day between YD365 and YD381 may represent the impact of atmospheric synoptic/microphysical events on Jan. 3-12 (YD368-377), in reasonable agreement with the $\sim 4-5 \mathrm{~mm} /$ day variability of the directly measured growth rates. In the T-profile growth rates, the growth rate variability amplitudes in late winter are comparable to those in early January, though they are much larger than those for the directly measured growth rates. The lagged correlation coefficient between the smoothed (7-day running mean) surface snow conductive flux at PITT (dashed line, Fig. 15d) and the three estimates of bottom ice growth is $0.90-0.95$, with peak correlations at lags ranging between 51 and $132 \mathrm{~h}$. The correlation between the 24-h running mean surface snow conductive flux and the same bottom growth rates is about 0.05 less with lag times about $10 \%$ less. The greater correlation and greater lag times for the smoothed surface fluxes makes physical sense, since surface forcing with longer time scales will penetrate deeper into the ice and should have a greater impact on the bottom ice growth rate.

It is unclear why the growth rate amplitudes from both the direct measurements and the T-profile technique, which is an attempt at hourly thickness estimates, are greater than those estimated from the internal heat conduction, $\mathrm{C}_{\mathrm{b}}$. Considering what is known about heat conduction, it makes sense that the $C_{b}$ amplitudes are less than the $F_{c}$ amplitudes (Fig. 15c, e). It is possible that the bottom is a mushy layer that is only partially frozen with a large amount of brine present, resulting in a much lower $\rho_{\text {ice }}$ in (5) and greater growth variability with limited heat conduction variability. Episodes of enhanced $\mathrm{F}_{\mathrm{O}}$ during the latter part of the winter could account for some of the periods of weaker observed ice growth during this time. Finally, it is also possible that lateral heat flux between bottom topography peaks and troughs produce greater response to variations in the heat conduction than expected from the heat conduction variations themselves. Regardless of the reason, these SHEBA data indicate that the atmospheric synoptic/microphysical forcing of the surface temperature in turn forces ice growth variations at the bottom of the multi-year sea ice of at least $\sim 1 \mathrm{~mm} /$ day and possibly as much as $5 \mathrm{~mm} /$ day. This is at least $20-33 \%$ of the observed variations of $3-5 \mathrm{~mm} /$ day, and possibly $100 \%$.

Measurements of ice growth rates with better temporal resolution and better accuracy are needed to more conclusively correlate the variability of surface energy fluxes with bottom growth rates and to define the time lag for the effect. However, this analysis strongly suggests that heat and moisture advection from lower latitudes and the occurrence of liquid-containing clouds directly impact midwinter ice growth rates. Moreover, this analysis provides a physical mechanism that involves long-range atmospheric transport, cloud microphysical processes, and the thermal/ conductive properties of the sea ice and snow cover.

\section{Discussion and conclusions}

Analysis of SHEBA observational data and ERA40 reanalysis data have led to the following conclusions:

1. Midwinter atmospheric pulses of moisture above the Arctic inversion in the Arctic Basin can be produced by long-range transport through the Fram Strait region and elsewhere. The time periods presented here suggest that periodic reductions in cloud fractions occur through lateral mixing of moist and dry air masses by mesoscale eddies rather than through a simple microphysical evolution to a clear state.

2. These moisture pulses are preceded by synoptic or mesoscale fronts, and often produce low-level, mixed phase stratocumulus $(\mathrm{Sc})$ clouds; for the midwinter SHEBA data, clear skies rarely occur for mid-level water vapor $\mathrm{Q}_{\mathrm{v}}>1 \mathrm{~g} \mathrm{~kg}^{-1}$.

3. The Sc clouds enhance $\mathrm{LW}_{\mathrm{d}}$ by $60-100 \mathrm{~W} \mathrm{~m}^{-2}$ because their emission heights are located at low levels generally near the base of their liquid tops in air that is substantially warmer than the upper tropospheric emission height of clear skies. Significantly greater $\mathrm{LW}_{\mathrm{d}}$ enhancements could have occurred if the clouds and emission heights had been within the core of the midlevel warm and moist air, though this is a dynamically unlikely location for their occurrence. The location of the liquid clouds relative to the warm air is hence likely 
a more important factor impacting $\mathrm{LW}_{\mathrm{d}}$ than the temperature of the warm and moist plume.

4. Liquid water in these clouds has a greater impact on the $\mathrm{LW}_{\mathrm{d}}$ than does the ice content, though the IWP also has an impact; a LWP $>10 \mathrm{~g} \mathrm{~m}^{-2}$ has a significant impact on $\mathrm{LW}_{\mathrm{d}}$, and LWP of these values appear to occur for $\mathrm{Q}_{\mathrm{v}}>0.6-1.2 \mathrm{~g} \mathrm{~kg}^{-1}$.

5. Through their $10^{\circ}-20^{\circ} \mathrm{C}$ impact on the surface temperature, clouds with significant liquid water affect compensatory processes such as the turbulent sensible heat flux, the outgoing longwave radiation, and the conductive flux in the snow and ice. These processes dampen the net effect of the large increase in $\mathrm{LW}_{\mathrm{d}}$. Furthermore, these responses present in the observations should also be present in models if their physical parameterizations include the key processes producing the responses.

6. Heat conduction via thermal waves associated with synoptic/mesoscale periods of significant LWP penetrate through the snow and multi-year sea ice, producing marked temperature increases and heat storage down to about $1.5 \mathrm{~m}$ into the ice. Associated changes in temperature gradients and internal heat conduction penetrate to $30-40 \mathrm{~cm}$ above the ice bottom, and perhaps even to the ice bottom, though only for atmospheric forcing events of at least several days in length. Effects from atmospheric events of shorter duration penetrate only to shallower depths. The amplitudes in the variations of heat conduction also dampen with depth. Observed variations in the rate of bottom ice growth of 3-5 mm/day may be due to cloud-induced variations of factors of 2-4 in the surface conductive heat flux and the penetration of the resultant thermal waves, though the damped amplitude of the heat conduction variations near the bottom of the ice only makes us confident that variations of $\sim 1 \mathrm{~mm} /$ day are clearly due to these atmospheric events. Hence, at least $\sim 20-33 \%$ of the bottom ice-growth variations are due to these atmospheric advective events, with the source of the remaining variability uncertain. Variations in bottom ice growth lag the surface energy flux forcing by several days up to $\sim 10$ days for ice $\sim 2.3$ m thick.

These conclusions are all observationally based and describe a sequence of events linking wintertime longrange advection of atmospheric heat and moisture into the Arctic Basin, formation of clouds with supercooled liquid water, enhancement of downwelling longwave radiation, enhancement of net surface energy fluxes, warming surface temperatures, reduction in conductive heat flux loss from the sea ice surface, warming of the sea ice interior, and reduction in ice bottom growth. Through this sequence of events, the frequency and number of wintertime moisture plume intrusions into the Central Arctic become important for the sea ice state. These events not only impact the surface temperature over the pack ice but also impact the amount of wintertime ice growth, and hence the ice thickness at melt onset in spring. Conceivably, the ice thickness at the time of melt onset could impact whether the ice melts completely during the summer and the date of this ice-free state. Hence, these wintertime events may impact the seaice evolution during the subsequent summer.

Since only one observational data set is available for a study such as this, some details in this sequence (e.g., water vapor thresholds for formation of supercooled liquid clouds) may be sensitive to factors not measured (e.g., aerosol/ice nuclei concentrations). However, the sequence of events is physically consistent with other studies examining various process components, such as cloud microphysics and heat/moisture advection into the Arctic.

The damping of heat conduction variations with depth also implies that these atmospheric forcing events will have a greater impact on wintertime ice growth rates for thin sea ice, which has become a more dominant ice characteristic in the Arctic because of the increasing fraction of first-year ice since SHEBA. For thinner ice, one might expect that the atmospheric events with liquid clouds would produce thermal waves that would have greater amplitude at the ice bottom than these SHEBA events had, and that atmospheric events with shorter time scales than those observed in this study would penetrate to the ice bottom. Hence, we hypothesize that such wintertime atmospheric events would have a potentially greater impact on the wintertime ice growth and subsequent summer ice evolution in the new Arctic conditions with thinner ice than they had in 1998.

Acknowledgments This study is greatly indebted to many people who labored hard during SHEBA to obtain arguably the world's best data set on air-ice-ocean interactions over the Arctic sea ice. The atmospheric and ice data sets used here are the results of efforts by C. Fairall, E. Andreas, P. Guest, T. Uttal, J. Intrieri, D. Gottas, D. Costa, J. Otten, S. Sandberg, R. Alvarez, D. Hazen, M. Mulhern, A. Keane, K. Claffey, R. Moritz, T. Grenfell, J. Richter-Menge, B. Light, W. Tucker III, H. Eicken, B. Elder, H. Bosworth, J. Govoni, R. Belyea, and J. Ukita. We also thank the crew of the Des Groseilliers. The data was collected using funding from the US National Science Foundation (NSF), National Aeronautics and Space Administration, and the Office of Naval Research. This analysis was funded by the NSF under grants ARC1023366 and ARC0714053. Some surface radiative flux measurements were provided by the US Department of Energy's Atmospheric Radiation Measurement Program. Helpful comments by reviewers led to significant improvements. We would like to make a special acknowledgment in memory of Edgar Andreas' contributions to the collection and analysis of the SHEBA data in particular and to the understanding of Arctic boundary-layer processes in general through a life dedicated to research. He was a scholar of the highest quality, and will be missed.

Open Access This article is distributed under the terms of the Creative Commons Attribution 4.0 International License (http:// 
creativecommons.org/licenses/by/4.0/), which permits unrestricted use, distribution, and reproduction in any medium, provided you give appropriate credit to the original author(s) and the source, provide a link to the Creative Commons license, and indicate if changes were made.

\section{References}

Doyle JG, Lesins G, Thackray CP, Perro C, Nott GJ, Duck TJ, Damoah R, Drummond JR (2011) Water vapor intrusions into the high Arctic during winter. Geophys Res Lett 38:L12806. doi: 10.1029/2011GL047493

Engström A, Karlsson J, Svensson G (2014) The importance of representing mixed-phase clouds for simulating distinctive atmospheric states in the Arctic. J Clim 27(1):265-272. doi:10.1175/ JCLI-D-13-00271.1

Grachev AA, Fairall CW, Persson POG, Andreas EL, Guest PS (2005) Stable boundary-layer scaling regimes: the SHEBA data. Bound Layer Meteorol 116(2):201-235. doi:10.1007/ s10546-004-2729-0

Grachev AA, Andreas EL, Fairall CW, Guest PS, Persson POG (2007) SHEBA flux-profile relationships in the stable atmospheric boundary layer. Bound Layer Meteorol 124(3):315-333. doi:10.1007/s10546-007-9177-6

Intrieri J, Shupe MD, Uttal T, McCarty BJ (2002) An annual cycle of cloud characteristics observed by radar and lidar at SHEBA. J Geophys Res 107(C10):8039. doi:10.1029/2000JC000423

Matejka TJ, Houze RA Jr, Hobbs PV (1980) Microphysics and dynamics of the clouds associated with mesoscale rainbands in extratropical cyclones. Q J R Meteorol Soc 106:29-56

Mauritsen T, Sedlar J, Tjernström M, Leck C, Martin M, Shupe M, Sjögren S, Sierau B, Persson POG, Brooks IM (2011) An Arctic CCN-limited cloud-aerosol regime. Atmos Chem Phys 11:165-173

Morrison H, deBoer G, Feingold G, Harrington J, Shupe MD, Sulia K (2012) Resilience of persistent Arctic mixed-phase clouds. Nat Geosci 5:11-17

Neff WD, Compo GP, Ralph FM, Shupe MD (2014) Continental heat anomalies and the extreme melting of the Greenland ice surface in 2012 and 1889. J Geophys Res Atmos 119(11):6520-6536. doi:10.1002/2014JD021470

Neiman PJ, Ralph FM, Wick GA, Lundquist J, Dettinger MD (2008) Meteorological characteristics and overland precipitation impacts of atmospheric rivers affecting the west coast of North America based on eight years of SSM/I satellite observations. J Hydrometeorol 9:22-47. doi:10.1175/2007JHM855.1

Overland JE, McNutt S, Groves J, Salo S, Andreas EL, Persson POG (2000) Regional sensible and radiative heat flux estimates for the winter Arctic during SHEBA. J Geophys Res 105(C6):14093-14102

Perovich DK, Elder B (2002) Estimates of ocean heat flux at SHEBA. Geophys Res Lett 29:9. doi:10.1029/2001GL014171

Perovich D, Andreas EL, Curry J, Eiken H, Fairall C, Grenfell T, Guest P, Intrieri J, Kadko D, Lindsay R, McPhee M, Morison J, Moritz R, Paulson C, Pegau S, Persson O, Pinkel R, RichterMenge J, Stanton T, Stern H, Sturm M, Tucker W, Uttal T (1999) Year on ice gives climate insights. EOS Trans Am Geophys Union 80:481-486

Perovich DK, Grenfell TC, Light B, Hobbs PV (2002) Seasonal evolution of the albedo of multiyear Arctic sea ice. J Geophys Res 107(C10):8044. doi:10.1029/2000JC000438

Perovich DK, Grenfell TC, Richter-Menge JA, Light B, Tucker WB III, Eicken H (2003) Thin and thinner: Sea ice mass balance measurements during SHEBA. J Geophys Res 108(C3): 8050. SHE 26-1-26-21. doi:10.1029/2001JC001079
Persson POG (2012) Onset and end of the summer melt season over sea ice: thermal structure and surface energy perspective from SHEBA. Clim Dyn 39:1349-1371. doi:10.1007/ s00382-011-1196-9

Persson POG, Uttal T, Intrieri JM, Fairall CW, Andreas EL, Guest PS (1999) Observations of large thermal transitions during the Arctic night from a suite of sensors at SHEBA. In: Preprints, 3rd symposium on integrated observing systems, 10-15 Jan 1999, Dallas, TX, pp 171-174

Persson POG, Fairall CW, Andreas EL, Guest PS, Perovich DK (2002) Measurements near the Atmospheric Surface Flux Group tower at SHEBA: near-surface conditions and surface energy budget. J Geophys Res 107(C10):8045. doi:10.1029/2000JC000705

Persson POG, Andreas EL, Bao JW, Fairall CW, Grachev AA, Guest PS, Jordan RE (2005) Determining wintertime heterogeneous pack ice characteristics and their impact on the aggregate atmospheric surface flux. In: Preprints, 8th conference on polar meteorology and oceanography, 9-13 Jan 2005, San Diego, CA

Pithan F, Medeiros B, Mauritsen T (2014) Mixed-phase clouds cause climate model biases in Arctic wintertime temperature inversions. Clim Dyn. doi:10.1007/s00382-013-1964-9

Pringle DJ, Trodahl HJ, Haskell TG (2006) Direct measurement of sea ice thermal conductivity: no surface reduction. J Geophys Res Oceans. doi:10.1029/2005JC002990

Ralph FM, Neiman PJ, Wick GA (2004) Satellite and CALJET aircraft observations of atmospheric rivers over the eastern North Pacific Ocean during the winter of 1997/98. Mon Weather Rev 132:1721-1745. doi:10.1175/1520-0493(2004)132<1721:SACA $\mathrm{OO}>2.0 . \mathrm{CO} ; 2$

Sedlar J, Tjernström M, Mauritsen T, Shupe M, Persson POG, Brooks IM, Birch CE, Leck C, Sirevaag A, Nicolaus M (2011) A transitioning Arctic surface energy budget: the impacts of solar zenith angle, surface albedo and cloud radiative forcing. Clim Dyn 37:1643-1660. doi:10.1007/s00382-010-0937-5

Sedlar J, Shupe MD, Tjernström M (2012) On the relationship between thermodynamic structure and cloud top, and its climate significance in the Arctic. J Clim 25(7):2374-2393

Sellers WD (1974) Heat transfer in soil. In: Physical climatology, 5th edn. University of Chicago Press, Chicago, pp 127-140

Shaw WJ, Stanton TP, McPhee MG, Morison JH, Martinson DG (2009) Role of the upper ocean in the energy budget of Arctic sea ice during SHEBA. J Geophys Res 114:C06012. doi:10.102 9/2008JC004991

Shupe MD (2007) A ground-based multiple remote-sensor cloud phase classifier. Geophys Res Lett 34:L22809. doi:10.1029/200 7GL031008

Shupe MD, Intrieri JM (2004) Cloud radiative forcing of the Arctic surface: the influence of cloud properties, surface albedo, and solar zenith angle. J Clim 17:616-628

Shupe MD, Uttal T, Matrosov SY (2005) Arctic cloud microphysics retrievals from surface-based remote sensors at SHEBA. J Appl Meteorol 44:1544-1562

Shupe MD, Matrosov SY, Uttal T (2006) Arctic mixed-phase cloud properties derived from surface-based sensors at SHEBA. J Atmos Sci 63:697-711

Shupe MD, Walden VP, Eloranta E, Uttal T, Campbell JR, Starkweather SM, Shiobara M (2011) Clouds at Arctic atmospheric observatories. Part I: occurrence and macrophysical properties. J Appl Meteorol Clim 50:626-644

Solomon A, Shupe MD, Persson POG, Morrison H (2011) Moisture and dynamical interactions maintaining decoupled Arctic mixed-phase stratocumulus in the presence of a humidity inversion. Atmos Chem Phys 11:10127-10148. doi:10.5194/ acp-11-10127-2011

Stefan J (1889) "Uber die Theorie der Eisbildung, insbesondere über die Eisbildung im Polarmeere", Sitzungsberichte de 
Mathematisch-Naturawissenschaftlichen Classe der Kaiserlichen. Akademie der Wissenschaften 98(2a):965-983

Sterk HAM, Steeneveld GJ, Holtslag AAM (2013) The role of snowsurface coupling, radiation, and turbulent mixing in modeling a stable boundary layer over Arctic sea ice. J Geophys Res Atmos 118:1199-1217. doi:10.1002/jgrd.50158

Stramler K, Del Genio AD, Rossow WB (2011) Synoptically driven Arctic winter states. J Clim 24:1747-1762

Sturm M, Perovich DK, Holmgren J (2002) Thermal conductivity and heat transfer through the snow on the ice of the Beaufort Sea. J Geophys Res 107(C21): 8043. SHE 23-1-SHE 23-17. doi:10.10 29/2000JC000409

Tjernström M, Graversen R (2009) The vertical structure of the lower Arctic troposphere analysed from observations and the ERA-40 reanalysis. Q J R Meteorol Soc 135:431-443. doi:10.1002/qj.380

Tjernström $\mathrm{M}$ et al (2005) Modelling the Arctic boundary layer: an evaluation of six ARCMIP regional-scale models using data from the SHEBA project. Bound Layer Meteorol 117:337-381. doi:10.1007/s10546-004-7954-Z

Tjernström M, Shupe MD, Brooks IM, Persson POG, Prytherch J, Salisbury D, Sedlar J, Achtert P, Brooks BJ, Johnston PE, Sotiropoulou G, Wolfe D (2015) Warm-air advection, air mass transformation and fog causes rapid ice melt. Geophys Res Lett 42(13):5594-5602. doi:10.1002/2015GL064373

Trodahl HJ, Wilkinson SOF, McGuiness MJ, Haskell TG (2001) Thermal conductivity of sea ice; dependence on temperature and depth. Geophys Res Lett 28(7):1279-1282

Uppala SM, Kållberg PW, Simmons AJ, Andrae U, Da Costa Bechtold V, Fiorino M, Gibson JK, Haseler J, Hernandez A, Kelly GA, Li X, Onogi K, Saarinen S, Sokka N, Allan RP, Andersson E, Arpe K, Balmaseda MA, Beljaars ACM, Van de Berg L,
Bidlot J, Bormann N, Caires S, Chevallier F, Dethof A, Dragosavac M, Fisher M, Fuentes M, Hagemann S, Holm E, Hoskins BJ, Isaksen L, Janssen PAEM, Jenne R, McNally AP, Mahfouf J-F, Morcrette J-J, Rayner NA, Saunders RW, Simon P, Sterl A, Trenberth KE, Untch A, Vasiljevic D, Viterbo P, Woollen J (2005) The ERA-40 re-analysis. Q J R Meteorol Soc 131:2961-3012

Uttal T, Curry JA, McPhee MG, Perovich DK, Moritz RE, Maslanik JA, Guest PS, Stern HL, Moore JA, Turenne R, Heiberg A, Serreze MC, Wylie DP, Persson POG, Paulson CA, Halle C, Morison JH, Wheeler PA, Makshtas A, Welch H, Shupe MD, Intrieri JM, Stamnes K, Lindsey RW, Pinkel R, Pegau WS, Stanton TP, Grenfell TC (2002) The surface heat budget of the Arctic. Bull Am Meteorol Soc 83:255-275

Walsh JE, Chapman WL, Portis DH (2009) Arctic cloud fraction and radiative fluxes in atmospheric reanalyses. J Clim 22:2316-2334. doi:10.1175/2008JCLI2213.1

Westwater ER, Han Y, Shupe MD, Matrosov SY (2001) Analysis of integrated cloud liquid and precipitable water vapor retrievals from microwave radiometers during SHEBA. J Geophys Res 106:32019-32030

Wettlaufer JS (2001) The Stefan problem: Polar exploration and the mathematics of moving boundaries. In: Hammerl C, et al (eds) Die Zentralanstalt für Meteorologie und Geodynamik, 18512001, 150 Jahre Meteorologie und Geophysik in Österreich. Leykam Buchverlagsges, Graz, pp 420-435. http://users.math. yale.edu/users/wettlaufer/articles/StefanFinal.pdf

Woods C, Caballero R, Svensson G (2013) Large-scale circulation associated with moisture intrusions into the Arctic during winter. Geophys Res Lett 40:4717-4721. doi:10.1002/grl.50912

Zhu Y, Newell RE (1998) A proposed algorithm for moisture fluxes from atmospheric rivers. Mon Weather Rev 126(3):725-735 